\title{
The Great Recession and Labor Market Adjustment: Evidence from Latvia
}

This is the peer reviewed version of the following article:

Original:

Lehmann, H., Razzolini, T., Zaiceva, A. (2020). The Great Recession and Labor Market Adjustment:

Evidence from Latvia. COMPARATIVE ECONOMIC STUDIES, 62, 149-181 [10.1057/s41294-019-00106-y].

Availability:

This version is availablehttp://hdl.handle.net/11365/1082286

since 2019-10-21T17:00:23Z

Published:

DOI:10.1057/s41294-019-00106-y

Terms of use:

Open Access

The terms and conditions for the reuse of this version of the manuscript are specified in the publishing policy. Works made available under a Creative Commons license can be used according to the terms and conditions of said license.

For all terms of use and more information see the publisher's website.

(Article begins on next page) 


\title{
The Great Recession and Labor Market Adjustment: Evidence from Latvia
}

\author{
Hartmut Lehmann \\ (University of Bologna, NRU Higher School of Economics and IZA; Strada Maggiore 45, 40125 \\ Bologna, Italy; hartmut.lehmann@unibo.it ) \\ Tiziano Razzolini \\ (University of Siena and IZA; Piazza San Francesco 7, 53100 Siena, Italy; \\ tiziano.razzolini.unisi@gmail.com ) \\ Anzelika Zaiceva* \\ (University of Modena and Reggio Emilia and IZA; Viale Berengario 51, 41121 Modena, Italy;
}

Tel: 0039- 059 2056848, E-mail: anzelika.zaiceva@unimore.it )

\begin{abstract}
How severe are costs to workers when the economy undergoes a large recession? In this paper we try to provide an answer to this question using as an example Latvia, a new EU member state, which faced the most severe recession in Europe and globally in 2008. We employ individual level Latvian Labor Force Survey and EU SILC data over the years 2002-2016 and 2007-2015, respectively, and analyze transitions in the labor market and their determinants as well as occupational mobility. Our results show that adjustment takes place predominantly at the extensive margin since it is driven by flows to unemployment. We also show that by 2016 the labor market has bounced back to its pre-crisis performance and that for the average worker Latvia's macroeconomic policies that focused on internal devaluation did not impose large costs in the medium run. However, the young, ethnic minorities and the less skilled were particularly affected by the crisis. Wage regressions suggest that job mobility is not associated with increase in wages, i.e., with increased labor productivity.

JEL Classification: J6, J21, P16.
\end{abstract}

Keywords: Unemployment, labor market flows, Latvia, crisis.

${ }^{*}$ Corresponding Author 


\title{
The Great Recession and Labor Market Adjustment: Evidence from Latvia
}

\begin{abstract}
How severe are costs to workers when the economy undergoes a large recession? In this paper we try to provide an answer to this question using as an example Latvia, a new EU member state, which faced the most severe recession in Europe and globally in 2008. We employ individual level Latvian Labor Force Survey and EU SILC data over the years 2002-2016 and 2007-2015, respectively, and analyze transitions in the labor market and their determinants as well as occupational mobility. Our results show that adjustment takes place predominantly at the extensive margin since it is driven by flows to unemployment. We also show that by 2016 the labor market has bounced back to its pre-crisis performance and that for the average worker Latvia's macroeconomic policies that focused on internal devaluation did not impose large costs in the medium run. However, the young, ethnic minorities and the less skilled were particularly affected by the crisis. Wage regressions suggest that job mobility is not associated with increase in wages, i.e., with increased labor productivity.
\end{abstract}

JEL Classification: J6, J21, P16.

Keywords: Unemployment, labor market flows, Latvia, crisis. 


\section{Introduction}

Latvia is a small open economy that joined the European Union (EU) in 2004 and has a population of around two million people. However, in the words of Blanchard et al. (2013), Latvia's adjustment and recovery from the 2008 economic crisis represents "a rare case study", which "has been an object of intense attention" (p. 325). After a period of transition to a market economy and structural reforms, the country enjoyed solid economic growth since the beginning of the 2000s. At the outset of the crisis it faced a decline in GDP of $25 \%$, and if the drop would have reached $30 \%$ as was predicted by the IMF it would have made Latvia's loss more than that of the US Great Depression in 1929-1933 (Weisbrot and Ray, 2010). The unemployment rate in Latvia increased the most in EU, from $6 \%$ in 2007 to close to $20 \%$ in 2009 and 2010 , making it the highest unemployment rate among the new EU members and one of the highest in the whole EU. It also faced significant emigration. Other two Baltic countries, Estonia and Lithuania, experienced similar trends.

Given this remarkable deterioration of economic conditions and the Latvian pegged exchange rate regime, devaluation seemed an obvious rescue scenario and was advised by many international experts. ${ }^{1}$ However, despite this advice, the authorities decided to maintain Latvia's currency peg and to adjust through internal devaluation and front-loaded fiscal consolidation. External devaluation was seen as inconsistent with the aim to join the Eurozone, and internal devaluation was also supported by the European Union. In all three Baltic countries, the policy response of radical reforms and fiscal adjustment was rapid, early and concentrated in the first half of 2009, with Latvia undertaking $60 \%$ of its needed adjustment within this year (Åslund, 2012). Large cuts in public expenditures were undertaken together with major structural reforms mainly in three sectors, namely public administration, health care and education (ibid). By the end of 2009, unit labor costs declined by almost $25 \%$ and remained stable thereafter, while productivity

\footnotetext{
${ }^{1}$ Also see, for example, Aslund and Dombrovskis (2011), Weisbrot and Ray (2010), Åslund (2012), Kattel and Raudla (2013). For the comprehensive macroeconomic analysis of the Latvian crisis, recovery and lessons for other countries see Blanchard et al. (2013).
} 
increased, with both labor shedding and a large increase in unemployment. The decline in the share of low productivity workers and firms' ability to reduce some $\mathrm{X}$-inefficiency were potentially behind this increase and set the stage for potential future growth (Blanchard et al., 2013). The fact that the productivity increase was not matched by the increase in wages suggests a crucial role played by increased unemployment, weak unions and limited employment protection (ibid). After 2012, however, Latvia has experienced fast wage growth and since 2013, wages rose faster than labor productivity. Emigration also played a role and there exist a positive correlation between unemployment in Latvia and emigration (see, e.g., Hazans 2019). ${ }^{2}$

There has been an intensive debate about the macroeconomic rationale and consequences of the policies chosen by the Latvian governments, including large wage cuts in the public sector as well as cuts in pensions and reductions in personal income tax allowances (see Blanchard et al. 2013). Krugman (2013) points to a poorly performing labor market long after the economy has bounced back from a large shock, while Forbes (2013) finds that "Latvia provides a model of an alternative response to a balance-of-payment crisis for countries that do not wish to devalue their currency." The recovery was also remarkable. The strong negative trend in GDP growth was soon overturned, with GDP growing at positive rates from the third quarter of 2010 onwards. Since 2010 Latvia has one of the largest GDP growth in the EU. Regarding unemployment, it has been declining steadily since 2010. Finally, Latvia adopted the Euro in 2014.

However, there has not been a careful study that assesses the costs to workers of macroeconomic policies that focus on internal devaluation. If we want to say something about these

\footnotetext{
${ }^{2}$ In this paper we do not discuss emigration from Latvia. A detailed analysis of Latvian emigration and its impacts is available in Hazans $(2013,2016)$, while Zaiceva and Zimmermann (2016) describe return migration during the crisis in the new EU member states. In the analysis that follows, unfortunately due to data limitations, we are not able to include emigration. Indeed, emigration potentially could constitute an additional labor market state in transition matrices. Nevertheless, we attempt to proxy potential emigration by looking at panel attrition. At any rate, as long as outmigration is an additional safety valve regarding large labor market shocks, which is clearly the case in Latvia, our analysis essentially shows lower bounds of labor market flows and labor market adjustment. In addition, when outmigration is not systematically correlated with the estimated labor market transitions, the presented adjustment trends over the Great Recession and in its aftermath remain credible. Indeed, as we show below, attrition only marginally affects the estimated transitions.
} 
costs we need to analyze labor market adjustment over the medium horizon, using micro data. We have spent a considerable amount of time to put the Latvian labor force survey (LFS) data into a form that allows us to analyze the flows between labor market states and their determinants, covering the years 2002 to 2016. We take our inspiration from Fallon and Lucas (2002), who document the impact of the financial crises of the 1990s on labor markets in Argentina, Mexico, Turkey and several Asian countries. Their evidence shows that in all these countries even when GDP returns to robust positive growth after the initial impact of the crisis, the negative effects in the labor market are longer lasting, with higher unemployment of heads of household, higher child labor and less long run human capital formation. It strikes us, therefore, as opportune to see whether and to what extent certain groups of workers are particularly hard hit by the crisis. Having more than a decade of data enables us to analyze the costs of labor market adjustment in the medium term, long after the crisis has run its course. In addition, we also employ EU SILC data for Latvia to analyze occupational mobility and wages over 2007-2015.

There are some papers on labor market adjustment in Latvia using micro data. For example, Fadejeva and Opmane (2016) employ Latvian LFS data and discuss internal labor market mobility between 2005 and 2014. The focus is, however, on institutions that further mobility in the labor market, it is less on the costs of adjustment as a result of the crisis. Zasova (2015) discusses labor market institutions as a vehicle to facilitate labor market recovery. Finally, Masso and Krillo (2011) discuss labor markets in the Baltic States during the crisis, but their detailed analysis with micro data is restricted to Estonia and does not include the recovery period. An interesting paper that uses similar estimation techniques is by Monastiriotis et al. (2019), which looks at transition dynamics in European labor markets during the crisis and recovery. The authors, however, cover all $28 \mathrm{EU}$ countries and there is little room for a detailed analysis of transitions in the Latvian labor market.

Our paper provides three contributions to the literature. First, we do some macro analysis that has not been done over such a long time span. For the years 2002 to 2016 we analyze labor 
market aggregates and assess whether contingent employment, underemployment and informal employment provide important adjustment mechanisms in the Latvian labor market to cushion the impact of the crisis. We also check whether job mobility has increased labor productivity. Second, a very careful and time consuming effort has resulted in a reliable panel data set that straddles more than a decade and that allows microeconomic analysis of labor market adjustment in one of the Baltic States. Our third contribution consists in establishing whether macroeconomic policies that use internal devaluation to address a balance-of-payment crisis generate large costs to some groups of workers in the medium run. This latter contribution is particularly relevant in the policy debate.

The rest of the paper is structured as follows. Section 2 presents economic and labor market conditions in Latvia during and after the Great Recession. Section 3 discusses the data sources and the definitions used, while section 4 presents the analysis of labor market trends. Section 5 looks at transition probabilities between labor market states and their determinants. Wage regressions are analyzed in Section 6. The final section provides conclusions and implications for policy.

\section{Data, definitions and the sample}

To investigate trends in the labor market and to estimate transitions between labor market states during and after the recession we employ both the longitudinal EU SILC data for Latvia ${ }^{3}$ as well as a panel dataset constructed by us from various waves of the Latvian Labor Force Survey over 20022016.

In order to estimate the labor market transitions we employ the Latvian Labor Force Survey (LFS), which has several advantages First, labor market status, i.e., employment, unemployment or inactivity, is constructed from the information available in the data using the conventional ILO

\footnotetext{
${ }^{3}$ There exist also EU SILC cross section data, which we do not use in this paper.
} 
definitions. It also contains information on ethnicity. In addition, we construct a regional variable for the labor market in the capital region (Riga and Pieriga), in the rest of the country as well as dummies for regions with a high, intermediate and low density of the population. The LFS has some drawbacks in that there is no information on informality for all the years as well as no information on wages. Thus, to estimate the incidence and determinants of informality over the empire period and to run wage regressions, we employ the EU SILC data.

Since one strength of the paper is the careful construction of the LFS panel, relying on the time structure of the interviews, we describe in some detail this time structure and how the panel was constructed. The LFS survey is constituted by four interviews (with the exception of the survey in the 2002-2004 period where there are only three interviews). The distance between the first and the second interview, and similarly the distance between the third and the fourth is 13 weeks. The distance between the second and the third interview is 39 weeks. We thus use transitions with a distance of 52 weeks between the first and third interviews and the second and the fourth interview (the latter is not available for the 2002-2004 period). When for the same individual we observe two transitions each transition is assigned a weight equal to $1 / 2$ (these weights are then used in the statistics on transitions and in the MNL estimations).

Only individuals who appear in two consecutive years and have no missing values in the current and lagged labor market status are retained in the sample. In addition, we only keep transitions between two different interviews in two consecutive years with at least 52 weeks of distance (92\% are exactly at 52 weeks of distance, the remaining $8 \%$ between 53 and 65 weeks). With this criterion we discard only $1.4 \%$ of individuals. ${ }^{45}$ In the final sample we keep individuals between 15 and 64 years old, who are not in the armed forces. ${ }^{6}$

\footnotetext{
${ }^{4}$ Note that sometimes for the same individual there are two possible transitions across two consecutive years: that is, the transition between the first and third interview, and the transition between the second and fourth interview. Both transitions occur with 52 weeks /one year of distance or slightly more. In these cases we use all transitions but implement some reweighting: for instance, to an individual with two possible transitions in the same year (e.g., $2007 / 2008$ ) we assign weights equal to 0.5 to each of the two transitions. If only one transition is available we assign a
} 


\section{Trends in the Latvian labor market between 2002 and 2016}

How did the Latvian labor market adjust to the largest negative GDP shock experienced in the EU?

We first look at labor market aggregates to see whether the labor market has recovered from the deep recession and if so how long this recovery took. To begin this analysis, we present descriptive evidence on the labor force participation rate, the employment rate, the unemployment rate without and with discouraged workers, as well as self-employment. ${ }^{7}$

Figures $1 \mathrm{a}$ and $1 \mathrm{~b}$ presents these aggregates, with all rates normalized by the working age population. Figure 1a shows a clear upward secular trend of the labor force participation rate between 2002 and 2016, only interrupted in the crisis years from 2009 to 2011, and reaching 75\% by the end of the period. The employment rate reaches a first peak in 2008 at $67 \%$, but then falls to $57 \%$ in 2010 and does exceed pre-crisis levels by 2016. The two unemployment rates in figure $1 \mathrm{~b}$ show a secular decline from 2002 until the crisis years and then rise quite dramatically in 2009 and reach a peak in the year 2010. After this peak year the unemployment rates are halved by 2016 and remain slightly higher than before the crisis. One needs to keep in mind, though, that the Latvian economy was strongly overheating before the crisis, resulting in a very tight labor market. Finally,

\footnotetext{
weight equal to one. Thus, the analysis is based on annual transitions. Note that analysis with annual data can be subject to the time aggregation bias (Shimer, 2012) or seasonality issues, and there is a strand of the literature that reveals the importance of these issues (see, for example, Nordmeier, 2014 and the references therein).

${ }^{5}$ We also drop observations with inconsistencies in the sequence number (e.g., the sequence number changes across waves or individuals with the same sequence number change gender or age category). The number of such cases, however, is small accounting roughly for $2 \%$ of all observations.

${ }^{6}$ The descriptive statistics and proportions of certain demographic groups in our sample with the LFS data as well as the EU SILC data are available upon request. The shares are comparable across the two datasets, apart for the Latvian/nonLatvian variable with the proportion of non-Latvians being larger in the LFS dataset. These two categories, however, are not directly comparable due to the fact that using the LFS data enables us to define Latvian and non-Latvian ethnicity, while the EU SILC variable refers to the country of birth.

${ }^{7}$ We follow Brown et al. (2006) in defining discouraged workers as individuals "not working, available but not searching for the following reasons: they believe that there are no available jobs, they do not know how to search, they believe they do not have suitable skills or are too old to find a job, they sought a job before but did not find one" (Brown et al., p. 449).
} 
the self-employment numbers do not show any major trends over the available years. Thus, the fall in employment during the crisis is essentially absorbed by a strong rise in unemployment. ${ }^{8}$

To extend our analysis, Figure 2 presents three measures of underemployment: the fractions of involuntary temporary workers, of involuntary part-time workers and of the underemployed broadly defined. ${ }^{9}$ The percentages of involuntary part-time workers are more than halved in the precrisis boom period, but then rise sharply after 2008 and reach a level slightly larger in 2016 than when the crisis set in. The share of involuntary temporary workers shows a similar trend but reaches the same negligible level in 2016 as it has in 2008. As far as the percentage of underemployed workers is concerned, it falls from roughly $10 \%$ in 2002 to below $4 \%$ in 2007 and 2008, but rises to a post-crisis peak of $8 \%$ in 2010 , decreasing to roughly $4 \%$ by 2016 . We find similar trends with Eurostat data for the three Baltic States, however, it is worth noting that during the crisis both unemployment and underemployment rates were the highest in Latvia among the Baltic States and higher than the EU average.

At any rate, underemployment shares are substantial, reaching in the crisis year of 2009 between $6 \%$ and $9 \%$ of all employed. Underemployment thus strikes us as another important channel besides unemployment, through which the Latvian labor market absorbs the shocks caused by the crisis. However, similar to the trends in labor market aggregates presented above, we can conclude that also with respect to underemployment the labor market does bounce back to a performance seen in the pre-crisis years.

Temporary employment is discussed in Lehmann et al. (2015). The authors suggest that it does not seem to be an adjustment mechanism when we look at all employees. They write: "For the

\footnotetext{
${ }^{8}$ probit regression results (available upon request) indicate that males and younger workers have a higher incidence of unemployment as do non-Latvians and workers with low educational attainment.

${ }^{9}$ Involuntary temporary workers are individuals in temporary jobs who could not find permanent jobs, while involuntary part-time workers would like to work full-time but could not find full-time jobs. Finally, underemployed workers are employed persons who work less than 40 hours per week but would like to work this amount of hours and are available to do so within two weeks.
} 
most part the fraction of employees with a temporary contract is very small throughout the period and rises only marginally from 2008 to 2009 (from around 4\% in 2007 to $4.5 \%$ in 2012). Only young and less educated workers have substantial shares of temporary workers, but these shares increase only marginally after the crisis." We, therefore, do not pursue temporary employment any further in this paper.

Another potential adjustment channel is informal employment. Defining informal employment is not an easy task. ${ }^{10}$ The Latvian LFS contains information on the lack of a written contract for employees that can be used to proxy informal employment. However, this information is only available since 2011. Employing this definition suggests a quite low incidence of informality for salaried employees in Latvia, around 2.4\% and 1.3\% in 2011 and 2012, respectively. In contrast, using the EU SILC data available over 2007-2015 allows us to establish the trajectory of informality before, during and after the crisis. Employing the EU SILC data, we construct two definitions of informal employment that are based on the approach of Koettl and Weber (2012) and of Hazans (2011). Definition 1 includes all employees as informal for whom their employers do not pay social security contributions. Non-professional employers or self-employed who employ five or fewer workers (including zero workers) are defined as informal self-employed. Also, unpaid family workers are also defined as informal. Definition 2 adds the informal self-employed and unpaid family workers to informal employees. ${ }^{11}$

Table 1 shows that the incidence of informal employment among dependent workers is particularly low in the crisis years of 2008 and 2009 - only in 2015 is this incidence lower. We observe the same trajectory when we include the self-employed and unpaid family workers. Thus, informal employment does not seem to have the buffer function during the crisis that one would

\footnotetext{
${ }^{10}$ See, for example, Lehmann and Zaiceva (2015) for different measures of informal employment in Russia. Their findings suggest that the incidence of informal employment depends crucially on the definition used.

${ }^{11}$ One form of "partial informality" are "envelope payments", i.e., when part of the wage is paid under the table to partially evade the payment of social security contributions. Unfortunately, there are no direct questions regarding envelope payments in the Latvian LFS or SILC questionnaires. Lehmann and Zaiceva (2015) show that in the Russian labor market this incidence reaches roughly $20 \%$ of all salaried employment in 2011.
} 
observe if the labor market were segmented and workers would use informal employment as a waiting stage. In Latvia overall employment and informal employment both decline during the downturn and informal employment until 2014 grows strongly after the economy picks up.

We report the importance of the factors determining informal employment for the pre-crisis year 2007, the crisis year 2011, and the years of recovery 2014 and 2015 in table B1 in the online appendix. ${ }^{12}$ Males have a higher incidence of informal employment than their female counterparts between 1.3 and 2.3 percentage points, holding other factors constant. This result is in line with the stylized fact that in transition countries males engage more in informal employment than females (Lehmann, 2015). Individuals with higher education attainment are less likely to be informal in 3 of the 4 years shown. When informal employment has a relatively small incidence in 2015 this effect is no longer statistically significant. In general, it is mostly low skilled individuals both with respect to education and occupation who have a higher likelihood to be informal. As far as sectors are concerned there are some changes over the period but informal employment is concentrated in agriculture, construction, hotels and restaurants, real estate and renting activities.

The upshot of the analysis of labor market trends in Latvia between 2002 and 2016 is that adjustment is very much at the extensive margin: the rise in unemployment with the onset of the crisis clearly dwarfs any other adjustment mechanism that we can think of, be it contingent or informal employment or underemployment. ${ }^{13}$ Given this strong predominance of unemployment, it strikes us as sensible to analyze transitions between the three standard labor market states and their determinants in detail.

\footnotetext{
${ }^{12}$ The online appendix is available at http://ftp.iza.org/dp9588_app.pdf.

${ }^{13}$.It is important to note that out-migration played also a very important role. Without the option to emigrate the unemployment rate would have been even higher (Hazans, 2013).
} 


\section{Transitions between labor market states and their determinants}

In this section we complement the descriptive analysis of labor market trends during the recession presented above with the estimates of transition probabilities and their determinants. We employ data from the Latvian LFS. The analysis is performed from the year 2002 till the last available year, i.e. 2016. We focus on three standard labor market states, namely employment, unemployment and inactivity.

\subsection{Methods}

Our analytical approach follows Clark and Summers (1979) and Bellmann et al. (1995) in assuming that transitions between labor market states are governed by a Markov process. Having the states of employment $(\mathrm{E})$, unemployment $(\mathrm{U})$ and inactivity $(\mathrm{N})$, we have nine potential transitions, which can be represented by the following matrix $P_{k}$ :

$$
P_{k}=\left[\begin{array}{ccc}
E E_{k} & E U_{k} & E N_{k} \\
U E_{k} & U U_{k} & U N_{k} \\
N E_{k} & N U_{k} & N N_{k}
\end{array}\right]
$$

where $U E_{k}$, for example, represents the probability of individual $\mathrm{k}$ being employed in period $\mathrm{t}$ conditional on being unemployed in period $\mathrm{t}-1$. The gross probability of transition from state $\mathrm{i}$ to state $\mathrm{j}$ can be written as:

$$
P_{i j}=\frac{F_{i j}}{S_{i}}, \quad i, j=e, u, n
$$

where $F_{i j}$ is the number of persons flowing from state $\mathrm{i}$ in period $\mathrm{t}-1$ to state $\mathrm{j}$ in period $\mathrm{t}$ and $S_{i}$ is the number of persons in the origin stock in period t. Finally, under Markovian assumptions duration of state occupancy is exponentially distributed and given by the reciprocal of the outflow rate: 


$$
\frac{1}{\sum_{j} P_{i j}}, j \neq i
$$

We look here at annual transitions, i.e., where the interviews are 51 or 52 weeks apart. Using annual transitions allows us to include sectoral and occupational covariates in multinomial logit estimation of transitions from employment, which are only available at an annual basis. Annual transition estimates might be subject to biases if we have substantial "round-tripping" 14 or if individuals change labor market status more than once per year. Since we have 3 or 4 interview dates over the year we have checked whether "round-tripping" or multiple labor market states over the year are present. Analyzing annual transitions, we found negligible shares of "round-trippers" and those who changed labor market status more than once per year. ${ }^{15}$

The Latvian labor market trends between 2002 and 2016 can be clearly divided into a precrisis, a crisis and a recovery period, the years 2002-2006 ${ }^{16}, 2008$ - 2011 and 2012-2016 respectively. We, therefore, average the annual transition probabilities and estimate multinomial logit regressions, covering the three labor market states, across these sub-periods. In addition, we dig a bit deeper into the question who particularly suffers from the crisis by estimating multinomial logit models by gender over the whole period and by the three sub-periods and provide predictions of labor market transitions for individuals with selected characteristics.

\subsection{Results}

Table 2 shows the estimated annual transitions based on equation 2, averaged over the years of the three sub-periods. ${ }^{17}$ This table suggests a large difference of these transitions for the pre-crisis and recovery periods, on the one hand, and the transitions of the years of the crisis, on the other

\footnotetext{
14 "Round-tripping" means that an individual moves over the year back to the original labor market state and hence appears as a non-mover.

${ }^{15}$ These results are available upon request.

${ }^{16}$ The transition from 2006 to 2007 is missing due to different coding of households. We, therefore, can only use the time interval between 2002 and 2006.

${ }^{17}$ Fadejeva and Opmane (2016) analyze determinants of flows from employment to unemployment and from unemployment to employment for the pre-crisis, crisis and post-crisis periods estimating Cox proportional hazard models.
} 
hand. Comparing the employment-unemployment $(E U)$ columns in the three sub-periods we see a doubling of the flows from employment to unemployment. The results of the multinomial regressions that we discuss below imply that this dramatic increase is mainly due to labor shedding and not due to voluntary quits since EU flows are particularly large in sectors that are especially hard hit by the crisis.

Slicing the data by educational attainment shows that in all years workers with only primary education have much larger outflows from employment that workers with secondary or higher educational attainment. The data also show large jumps in the transition rates between the pre-crisis and crisis years for all workers, but this jump is particularly pronounced for workers with only primary education. Disaggregating the data by gender shows that it is males who are much more affected by the increase in labor shedding since women's transition rate from employment to unemployment is much lower in the crisis period. To see whether this result can be explained by the sectoral composition of employment we inspect the marginal effects of the determinants of transitions from employment by gender in the online appendix (tables B3 and B6). A comparison of the marginal effects demonstrates that it is above all the sectors manufacturing and construction that explain the higher outflow rate from employment for male workers, since in both sectors men dominate and since for construction the marginal effect in the male regression is nearly twice as large as for females, while the marginal effects of manufacturing are roughly equal. It is also noteworthy that the marginal effect of elementary occupations, where male workers are more concentrated, is large with nearly 5 percentage points for men and 3 percentage points for women. Hence it is the sectoral and to some degree also the occupational composition pre-crisis that explains the much larger male outflows from employment during the crisis years.

Slicing the data by age we get expected results, the EU flows are much larger for young workers than for middle-aged and older workers, while both young and older workers have relatively large outflows into inactivity. In the crisis years the EU and EN transitions jump upwards, 
maintaining the same relative magnitudes. Latvians have slightly lower transitions from employment in all sub-periods than non-Latvians, but these differences are clearly not marked. Finally, looking at the regional dimension we do not find large differences in transition rates from employment no matter where an individual resides. Summarizing the presented evidence thus far, males, young workers and workers with primary education are the hardest hit by the crisis, as they have the highest transition rates from employment into unemployment.

Table 2 also shows that transitions from employment return roughly to pre-crisis levels in the years 2012 to 2016. So, on the basis of these flows we can say that the costs of labor market adjustment in the medium run seem tolerable. We will discuss at the end of this section whether heterogeneous experiences hide behind this benign outcome regarding average flows when it comes to bearing the costs of adjustment.

Columns 4-6 in Table 2 show what happens to the unemployed. Applying equation 3, one important statistics is the average duration of unemployment which is given by the reciprocal of the sum of the transition probabilities UE and UN. In the pre-crisis sub-period this expected duration is $(1 / 0.554)=1.8$ years, in the years of the crisis 1.73 and in the recovery sub-period 1.76 years respectively. Hence on this measure we do not observe a deterioration in the labor market. It is also worth noting that in the crisis sub-period outflow rates into employment are at least as high as before and after the crisis. However, a similar outflow rate in combination with a large inflow rate into unemployment in the aftermath of the crisis still implies the build-up of the stock of long-term unemployed.

Inspection of the outflow rates into employment (UE) enables us to determine which groups have particularly large difficulties in leaving unemployment for new jobs. Workers with primary education have a substantially worse experience than their better educated counterparts. In addition, older workers (55-64 years of age) have relative difficulties to find employment, while their transition rates into inactivity are particularly large. What is also worth noting is that females have 
similar outflow rates into employment as men independent of the sub-period considered, but that they withdraw from the labor market much more than men during the crisis years, having a UN rate that is 10 percentage points larger than the male rate. So, it is not obvious whether men have a really worse labor market experience in the crisis years compared to women. It is true that there is more labor shedding of male workers but women seem to become much more discouraged as they leave unemployment for inactivity in large numbers.

Behind the averages for sub-periods we can find dramatic changes in the transitions from employment and unemployment if we compare these transitions between the boom period of 2007 to 2008 with the main crisis period 2008 to 2009 . These transitions are shown in table A2 in the appendix. In the boom period we have very low transition rates from employment into unemployment apart from young workers and workers with primary education. At the same time apart from this latter category and older workers more than half the unemployed find a job within a year. The shown transitions in panel a of table A2 can be associated with labor market flows in an overheated economy. The picture for the crisis year is very different. EU flows triple between the two time intervals and outflows from unemployment is roughly halved.

However, in our opinion it would be misleading to contrast the boom year and the main crisis year and infer from this comparison how well the Latvian labor market adjusts to the large macro shock; averaging transition probabilities over the three sub-periods gives a better picture of how the labor market relatively rapidly adjusts to this shock. On the basis of the estimated transition matrices we can conclude that the main adjustment of the Latvian labor market to the negative shock occurred between 2008 and 2010. We can also see that labor market transitions return roughly to pre-crisis levels if we extend the analysis up 2016. The analysis of the labor market aggregates and the discussion of the transition probabilities at any rate point to unemployment as the main absorbing state in response to the shock brought on by the crisis. 
The determinants of the transitions from the respective origin state to the respective destination states are estimated with a multinomial logit (MNL) model. Marginal effects of a variable on the transition probabilities into a specific state are presented, that show the impact of a single variable on the transition probability of interest, holding all other factors constant. We also report the effect of a variable on the "transition probability" of remaining in the origin state. For example, table 3 shows employment as the origin state and the marginal effects of a set of variables on the transition probabilities from $\mathrm{E}$ to $\mathrm{E}(\mathrm{E}-\mathrm{E})$, from $\mathrm{E}$ to $\mathrm{U}(\mathrm{E}-\mathrm{U})$ and from $\mathrm{E}$ to $\mathrm{N}(\mathrm{E}-\mathrm{N})$.

With employment as the origin state, where we control for sectors and occupations, the positive marginal effect for the male dummy with respect to flows into unemployment is significant in the crisis year, while it is insignificant in the other sub-periods. So, during the crisis labor shedding affected men disproportionately even when we control for the sectoral and occupational composition of employment, with the exception of the flows into inactivity which has a negative sign. Age affects transition into unemployment especially strongly since the core age group has roughly a 1.3 percentage points lower probability to flow into unemployment and a 1.5 percentage points lower probability to flow into inactivity than workers in the youngest group. The probabilities of older workers are -3.1 and 4.3 percentage points respectively when considering transitions into unemployment or into inactivity. Latvian workers also have a somewhat better labor market experience during the crisis than non-Latvians since their proclivity to enter unemployment is about 1 percentage point lower than that of non-Latvians. Finally workers with upper secondary and in particular with tertiary education have a substantially lower likelihood to enter unemployment and to leave the labor force than less educated workers. This result holds for both the crisis years and the years of recovery.

The marginal effects on sectors and on occupations are especially large in the crisis years. In particular, workers in construction have a probability of leaving for unemployment that is nearly 8 percentage points higher than the probability for workers in agriculture and fishery. Other sectors where workers disproportionally lose jobs are real estate, trade, accommodation and food services 
and mining and manufacturing. As far as occupations are concerned service workers, craft workers and workers in elementary occupations have a relatively high likelihood to flow into unemployment. Overall, it is workers with lower skills who are particularly affected by job loss. It is striking that the large and significant impact of job loss for workers in certain sectors and occupations essentially only holds for the crisis years.

The MNL estimates of transitions from unemployment show some interesting patterns (table 4). Male workers have a higher likelihood to remain unemployed even though flows into employment are larger by 3.6 percentage points. This longer unemployment duration comes about because their flows into inactivity is roughly 10 percentage points smaller than the corresponding flows of female workers. Unemployed workers residing in Riga and surroundings have a higher probability of entering employment only in the recovery years while in the pre-crisis and crisis subperiods residence plays no role. Age is also an important determinant of flows out of unemployment. The core age group has a substantially longer duration of unemployment than young and older workers only because they have a substantially lower probability to leave unemployment for inactivity. Older workers, on the other hand, have lower flows into employment and larger flows into inactivity than the rest of the workforce. Ethnicity is an important determinant of transitions out of unemployment since Latvian workers leave unemployment at a significantly higher rate than non-Latvians because of a much higher transition rate to employment that amounts to between 5.9 and 8.6 percentage points during the entire reported period. These results that ethnic minorities have a worse performance than the majority in terms of employment are in line with previous findings for Latvia (Hazans 2010, 2011, 2013). Finally, as expected, better educated workers have higher accession rates to jobs and lower transition rates into inactivity. Last but not least, workers with children have higher job accession rates.

Marginal effects of the determinants of transitions out of inactivity are reported in table 5. Male workers have a higher proclivity to enter the labor force, and this through entry into both 
employment and unemployment. While residence has hardly ever an impact on flows out of inactivity, age and educational attainment are very important determinants of these flows. Workers in the core age group have higher flows into both employment and unemployment while older workers remain disproportionally inactive because of much lower flows into employment. Workers with upper secondary and tertiary education have much higher transition rates into employment than their less educated counterparts. Finally ethnicity also plays a role since Latvians access jobs at a rate that is between 2 and 3 percentage points higher than the job accession rate of non-Latvians. The effect is, however, minor since both education and age exhibit substantially larger marginal effects than ethnicity.

One issue that can confound this analysis is attrition, out-migration being one of the potential reasons for it. Selective out-migration and attrition might bias our results if the flow of persons who drop out of the survey is correlated systematically with the transitions between labor market states. Respondents are interviewed at most four times in two consecutive years, for example, in the $1^{\text {st }}$ quarter $2007,2^{\text {nd }}$ quarter $2007,1^{\text {st }}$ quarter 2008 and $2^{\text {nd }}$ quarter 2008 . As this interview structure shows, the distance between the first and third interview is one year. Since we estimate annual transition probabilities we can define future attriters as respondents who appear in the first three interviews but are not present in the fourth interview. To tackle the issue of attrition and potential emigration, we perform separate regressions with the same covariates where the transitions are restricted to the flows between interview 1 and 3 and in which we add an attrition dummy for those who have no fourth interview. The coefficient estimates of the attrition dummy are reported in the last row in tables 3 - 5. Since there is no fourth interview in the years 2002 to 2006, we report the coefficient on future attriters only for the crisis and recovery years.

The important result regarding the coefficient estimates on the attrition dummy in Table 3 is that flows from employment into unemployment are slightly over-estimated when we concentrate on the sample of non-attriters. However, this effect is quite small as a comparison of the marginal 
effects of the other covariates and the coefficient on the attrition dummy shows. Table 4 , on the other hand, shows that attrition, as modeled by us, does bias the flows from unemployment into employment only marginally, while concentrating on non-attriters does not produce any overestimate as far as exiting the labor force from the state of unemployment is concerned. Finally, flows from inactivity into employment are slightly under-estimated in the crisis years when we ignore attrition (see Table 5), although the effect is tiny compared to the large marginal effects of some determinants. This exercise leads us to conclude that while attrition might bias our results in a negligible way, it does not seem to strongly affect the transitions from employment, unemployment and inactivity and that the large flows between labor market states that we find during the Great Recession are certainly not driven by attrition. ${ }^{18}$

Tables $6-9$ present predicted transition probabilities for a selected group of individuals using the parameter estimates in tables B3 to B7 in the online appendix. The detailed multinomial logit estimates done separately for men and women and derived for the entire period $(2002-2016)$ and for the 3 sub-periods allow us to show the heterogeneous experience that workers have in the Latvian labor market around the great recession. By looking also at the entire period we can see how selected individuals fare over an extended period. We start off with the predicted transitions out of employment (table 6). The large variation is striking especially if we look at the values for men in the crisis years. This variation is somewhat attenuated for women. Older non-Latvian male workers with low skills and working in low level occupations are especially hard hit not only during the crisis but throughout the reported period. Young low skilled male workers working in

\footnotetext{
${ }^{18}$ We have also estimated transitions and their determinants disaggregating employment into four mutually exclusive states: permanent wage employment, temporary wage employment and professional and non-professional selfemployment (available upon request). In all periods the states permanent wage employment, professional and nonprofessional self-employment as well as inactivity were relatively "stable". In contrast, temporary wage employment was always very volatile since between 2007 and 2011 more than $70 \%$ of workers who are originally in this state exit it for other destinations. In other words, more than two thirds of all workers who at the beginning of the year were in temporary wage employment found themselves in another state at the end of the year. During the crisis period of $2008-$ 2009 , both for workers in permanent wage employment and in non-professional self-employment the inflow rates into unemployment triple, while around a quarter of workers originally in temporary wage employment flow every year into unemployment throughout the entire period. Overall, this analysis also suggests that the only relevant adjustment for the large majority of workers who are in permanent wage employment is at the extensive margin, that is, through flows into unemployment.
} 
manufacturing and in elementary occupations have a similar bad experience in the labor no matter which sub-period one looks at. In contrast highly skilled workers with children working in the financial sector, independent of gender, experience a job separation rate that is at least 3 times smaller than for their low skilled counterparts.

Among the unemployed, highly educated middle-aged male workers have a job accession rate that is more than twice as large as the rate for older non-Latvian male workers with only primary education, while the exit rate from the labor force is less than half the exit rate of their less skilled counterparts (see table 7). These relative magnitudes are found in all sub-periods, but they are slightly attenuated among women. Finally, table 8 shows that entry from inactivity into the labor force is above all determined by education since both middle-aged and young workers with high educational attainment enter both employment and unemployment at far higher entry rates than workers with less educational attainment. This dominant role of education regarding transitions from unemployment and inactivity into employment and the labor force holds for both sexes.

\section{Wages and occupational mobility during and after the crisis}

After having analyzed the transitions between different labor market states, in this section we complete the picture by looking further at the mobility within employment and investigating job-tojobs moves and their impact on wages.

In particular, we investigate whether labor mobility across occupations and sectors can lead to a more efficient structure of job matches in the economy, resulting in higher productivity and thus higher wages. We start out with a very simple exercise, performing wage regressions and including a dummy for those workers who changed jobs from one year to the next. To this aim, we employ the annual EU SILC longitudinal data over the period 2007-2015 and estimate pooled OLS and fixed effects wage regressions with standard covariates. In some specifications we also include aggregated occupational groups. 
Column 1 of Table 9 reports the results of an OLS regression of the log of real monthly wages on a quadratic in age, gender, educational attainment and year dummies. Since occupational choice is endogenous and sorting into occupations may bias the results, we aggregate occupations into four large groups and also exclude occupational groups in column 1 to see how robust our estimates are. Consistent with earlier studies for Latvia, wages are rising in age at a decreasing rate, and there is a quite large gender wage gap as well as large returns to education. These results hold when we include occupational groups in column 2, with the gender gap actually increasing to roughly 32 percent. Adding a dummy for annual job-to-job moves again does not change the coefficient estimates (column 3). The crucial result here is that the mobility dummy is negative and large, implying that those who change jobs experience a wage penalty on average.

These OLS results are biased if one cannot control for unobservable characteristics that influence significantly both wages and covariates, such as ability or motivation. The fixed effects results in column 4 account for unobserved time-invariant workers' characteristics and show no wage penalty caused by a job change. Hence a wage penalty seems to arise because of adverse selection. In other words, workers who change jobs have on average worse unobserved characteristics than those who are able to retain their jobs.

To probe somewhat deeper into the issue of job change and wages we create three mutually exclusive dummy variables: a variable for upward mobility, that is for movements from a higher numbered occupational group to a lower numbered occupational group, a variable for downward mobility, which describes the opposite movement and a variable when a job change entails no movements between occupational groups. We then interact these mobility dummies with the job change dummy in our wage regressions. Table 10 shows the coefficients on these interaction terms. In column 2 we do not control for occupational group while in column 3 occupational group is an additional control variable. When we do not control for occupational group the coefficients of the interaction terms show small differences across the three mobility groups that are not statistically significant. Once we control for occupational group we get statistically significant differences as far 
as upward and downward mobility is concerned. Those workers who are upwardly mobile do not experience a wage penalty when they change jobs, while those who move down in the occupational ladder are confronted with a $33 \%$ wage penalty. In the light of the standard errors the difference between the zero and the $33 \%$ penalty is statistically significant, while the difference in the penalties of those who move down and those who stay in the same occupational group albeit numerically large is not statistically significant.

Why do we not observe a wage premium for those who are occupationally upwardly mobile? Having no information on where these workers come from and in which firms they land their new jobs we can only speculate. A negative impact of the business cycle may definitely play a role. Selective out-migration may be another reason when those with a particularly high likelihood of improved productivity move out. Third, and maybe most importantly, as long as within firms there exists an upward sloping wage profile with respect to tenure (for example, because of a seniority pay system or because of the accumulation of firm specific human capital), workers will lose their positions in the previous firms' wage structure when they change jobs. Starting a new job, they will have lost firm specific human capital and all the tenure accumulated with the previous employer (see Lehmann and Wadsworth 2000 on this). Only in the case of strong upward occupational mobility, which is the case when workers move from a higher to a lower numbered occupational group, will workers in their new job not face a lower wage than in their previous employment. Interpreting the absence of a wage penalty for workers who show strong upward occupational mobility in this way allows us to infer that part of the observed labor reallocation may result in improved productivity in the Latvian labor market during and after the crisis. However, for most years we have more upward than downward mobility and the vast majority of job changers remain in the same occupational group throughout the period. Hence according to this evidence overall job reallocation does not seem to lead to an increase in labor productivity and higher wages during and shortly after the crisis. 


\section{Conclusions and policy implications}

In this paper we analyze labor market adjustment to a large macroeconomic shock in Latvia, a country that faced the largest recession and fiscal adjustment in Europe and a subsequent remarkable recovery. To cope with the crisis, internal devaluation was chosen by the Latvian authorities, and several important reforms were undertaken, including institutional reforms in the labor market.

Even though the macroeconomic crisis has been overcome (Blanchard et al.,2013) and strong GDP growth has resumed since the third quarter of 2010, the performance of the Latvian labor market did not bounce back to its pre-crisis level by 2012. All analyzed labor market aggregates show a worse performance in 2012, i.e., 3 years after the crisis than in the years 2007 2008, when the labor market experienced a strong boom. However, if we extend the analysis up to 2016 we can clearly state that the labor market aggregates have returned to pre-crisis levels, especially if we abstract from 2007 when the Latvian economy was overheating. So, with a long enough perspective we do not see major costs in the labor market if we rely on labor market aggregates. The second result from the aggregate analysis is that the only truly relevant adjustment mechanism was the very large inflow into unemployment, while contingent employment, informal employment and underemployment all played negligible roles during the crisis and in its aftermath. Hence, increasing unemployment entitlement to 9 months was a policy cushioning to some degree the income reduction of many workers in Latvia who entered unemployment.

The transition analysis gives us a similar picture in that labor market transitions between the standard labor market states employment, unemployment and inactivity return to pre-crisis transition levels once we extend the analysis to 2016. So, on the basis of annual transitions between labor market states we can state that workers on average are not worse off in the recovery period compared to the pre-crisis years. Said differently, the macroeconomic policies focusing on internal devaluation did not cause damages to the average worker in the Latvian labor market. On the other 
hand, the predicted labor market transitions based on very detailed multinomial logit estimates show a less rosy picture for some groups of workers. Even in the medium run, the less skilled, the less educated, the young and the old if low skilled as well as non-Latvians are particularly hard hit by the crisis. In addition, the predicted transitions from unemployment and inactivity make it abundantly clear that what truly matters for a good labor market performance is an individual's educational attainment. Policies that promote skill formation seem an important measure to soften the impact of crises in the medium run.

Furthermore, our complementary wage regression results and the analysis of the job-to-job mobility indicate that occupational mobility does not lead to an increase in wages, and thus in labor productivity in the Latvian labor market during and after the crisis, hinting at the fact that during the Great Recession many workers probably change jobs involuntarily. If anything, there is evidence of a negative correlation between downward occupational mobility and wages. Finally, the role of migration is also important. Although the data at our disposal does not allow us to directly evaluate the effect of out-migration, the estimated panel attrition probabilities suggest that our analysis is not to any major degree biased by selected attrition. Nevertheless, further research is needed with outmigration included as one of the states, as well as the analysis of the impact of emigration and return migration on labor markets, demographic trends and political economy. 


\section{References}

Åslund, A. 2012. Lessons from Reforms in Central and Eastern Europe in the Wake of the Global Financial Crisis. Peterson Institute for International Economics. Working Paper No. WP $12-7$

Bellmann, L., Estrin, S., Lehmann, H. and Wadsworth, J. 1995. The Eastern German Labor Market in Transition: Gross Flow Estimates from Panel Data. Journal of Comparative Economics, vol.20(1): 137-170.

Blanchard, O. J., M. Griffiths, and B. Gruss. 2013. Boom, Bust, Recovery: Forensics of the Latvian Crisis. Brookings Papers on Economic Activity, Fall 2013: 325-388.

Brown, D.J., J.S. Earle, V. Gimpelson, R. Kapeliushnikov, H. Lehmann, A. Telegdy, I. Vantu, R. Visan, and A. Voicu. 2006. Nonstandard Forms and Measures of Employment and Unemployment in Transition: A Comparative Study of Estonia, Romania, and Russia. Comparative Economic Studies, 48: 435-457.

Clark, K. and Summers, L. 1979. Labor Market Dynamics and Unemployment: a Reconsideration. Brookings Papers on Economic Activity, Spring: $13-60$.

Fadejeva, L. and Krasnopjorovs, O. 2015. Labor Market Adjustment during 2008 - 2013 in Latvia: Firm Level Evidence, Latvijas Banka, Working Paper No. 2/2015.

Fadejeva, L. and Opmane, I. 2016. Internal Labour Market Mobility in 2005-2014 in Latvia: The Micro Data Approach, Baltic Journal of Economics, 16:2, 152-174.

Fallon, P. and Lucas, R. 2002. The Impact of Financial Crises on Labor Markets, Household Incomes and Poverty: A Review of Evidence. The W.B. Research Observer, 17(1): 21-45.

Hazans, M. 2016. Migration Experience of the Baltic Countries in the Context of Economic Crisis. In: Martin Kahanec and Klaus F. Zimmermann (eds), Labor Migration, EU Enlargement, and the Great Recession. Springer: Berlin et al.: 297-344.

Hazans, M. 2013. Emigration from Latvia: Recent trends and economic impact", in OECD, Coping with Emigration in Baltic and East European Countries, OECD Publishing, Ch. 4: 65-110. 
Hazans, M. 2011. Labor market integration of ethnic minorities in Latvia. In: Martin Kahanec and Klaus F. Zimmermann (eds), Ethnic diversity in European labor markets: Challenges and solutions, Cheltenham, UK - Northampton, MA, USA: Edward Elgar: 163-197.

Hazans, M. and K. Philips. 2010. The Post-Enlargement Migration Experience in the Baltic Labor Markets. In: M. Kahanec and K. F. Zimmermann (eds), EU Labor Markets After PostEnlargement Migration, Berlin - Heidelberg: Springer: 255-304.

Ivlevs, A. and M. Veliziotis. 2017. What Do Unions Do in Times of Economic Crisis? Evidence from Central and Eastern Europe. European Journal of Industrial Relations, vol. 23(1): 8196.

Kattel, R. and R. Raudla. 2013. The Baltic Republics and the Crisis of 2008-2011. Europe-Asia Studies, 65 (3): 426-449.

Koettl, J. and M. Weber. 2012. Does Formal Work Pay? The Role of Labor Taxation and Social Benefit Design in the New EU Member States, Research in Labor Economics, 34: 167204.

La Porta, R. and Shleifer, A. 2008. The Unofficial Economy and Economic Development. Brookings Papers on Economic Activity, Fall: 275 - 352.

Layard, R., Nikell, S. and Jackman, R. 1991. Unemployment . Macroeconomic Performance and the Labor Market, Oxford University Press.

Lehmann, H. 2015. Informal employment in transition countries: Empirical evidence and research challenges. Comparative Economic Studies, 57 (1): $1-30$.

Lehmann, H. and Pignatti, N. 2007. Informal Employment and Labor Market Segmentation in Transition Economies: Evidence from Ukraine. IZA Discussion Paper No. 3269. Institute for the Study of Labor, IZA, Bonn.

Lehmann, H. and Wadsworth, J. 2000. Tenures that Shook the World: Worker Turnover in Russia, Poland and Britain. Journal of Comparative Economics, vol. 28 (4): 639-664. 
Lehmann, H. and A. Zaiceva. 2015. Re-defining informal employment and measuring its determinants: Evidence from Russia. Journal of International Development, 27 (4): 464 488.

Monastiriotis, V. C. Macchiarelli, N. Lampropolou. 2019. Transition Dynamics in European Labour Markets During Crisis and Recovery, Comprataive Economic Studies, 61 (2), 213-234.

Nordmeier, D. 2014. Worker flows in Germany: Inspecting the time aggregation bias. Labor Economics, 28, 70-83.

OECD 2010. OECD Employment Outlook 2010. Moving Beyond the Jobs Crisis. OECD Publishing.

OECD 2014. Society at a Glance 2014: OECD Social Indicators. OECD Publishing.

Shimer, R. 2012. Reassessing the Ins and Outs of Unemployment. Review of Economic Dynamics, $15(2), 127-148$.

Zaiceva, A. and K. F. Zimmermann. 2016. Returning Home at Times of Trouble? Return Migration of EU Enlargement Migrants during the Crisis. In: Martin Kahanec and Klaus F. Zimmermann (eds), Labor Migration, EU Enlargement, and the Great Recession. Springer: Berlin et al.: $397-418$.

Zasova, A. 2015. Labour Market Measures in Latvia 2008-13: The Crisis and Beyond. International Labour Office, Research Department. Geneva: ILO, 2015. 
Table 1. Incidence of informal employment

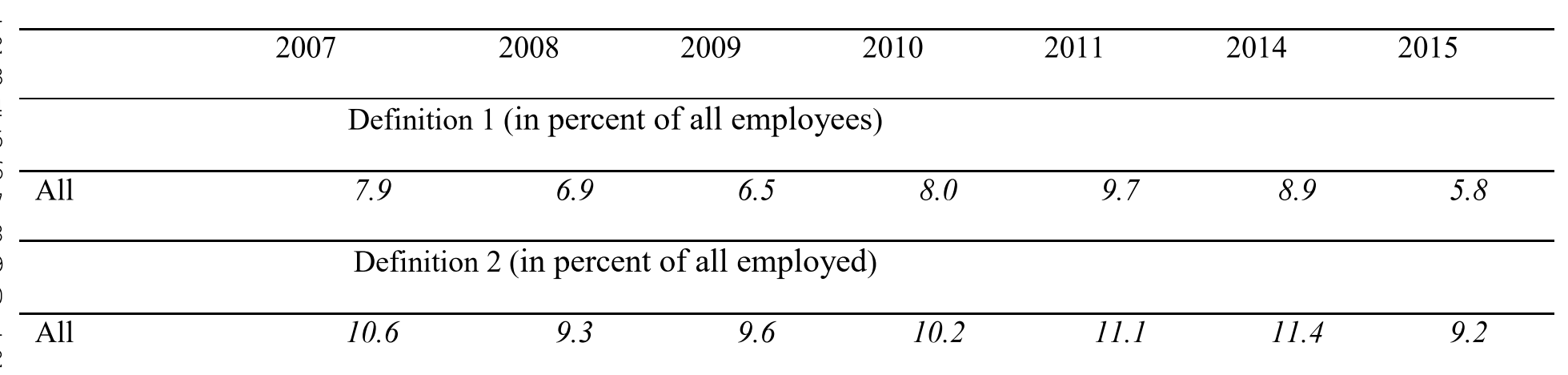

Sencentic 
Table 2. Annual labor market transitions averaged over sub-periods, Latvian LFS, 2002-2016

a) Pre-crisis: 2002-2006

\begin{tabular}{|l|c|l|l|l|l|l|l|l|l|}
\hline & EE & EU & EN & UE & UU & UN & NE & NU & NN \\
\hline All & 0.925 & 0.031 & 0.045 & 0.347 & 0.446 & 0.207 & 0.128 & 0.043 & 0.829 \\
\hline Tertiary & 0.961 & 0.013 & 0.026 & 0.352 & 0.432 & 0.216 & 0.281 & 0.075 & 0.644 \\
\hline Secondary & 0.923 & 0.033 & 0.044 & 0.373 & 0.455 & 0.172 & 0.173 & 0.055 & 0.772 \\
\hline Primary & 0.876 & 0.045 & 0.078 & 0.273 & 0.426 & 0.301 & 0.057 & 0.027 & 0.916 \\
\hline Male & 0.931 & 0.032 & 0.037 & 0.362 & 0.442 & 0.196 & 0.137 & 0.047 & 0.817 \\
\hline Female & 0.919 & 0.029 & 0.052 & 0.331 & 0.450 & 0.219 & 0.122 & 0.041 & 0.837 \\
\hline $16-24$ & 0.832 & 0.066 & 0.103 & 0.339 & 0.365 & 0.297 & 0.101 & 0.036 & 0.864 \\
\hline $25-54$ & 0.940 & 0.028 & 0.031 & 0.379 & 0.468 & 0.153 & 0.226 & 0.080 & 0.694 \\
\hline $55-64$ & 0.904 & 0.020 & 0.076 & 0.182 & 0.432 & 0.385 & 0.070 & 0.017 & 0.912 \\
\hline Latvian & 0.933 & 0.025 & 0.043 & 0.378 & 0.399 & 0.223 & 0.132 & 0.038 & 0.830 \\
\hline Non-Latvian & 0.912 & 0.040 & 0.047 & 0.314 & 0.496 & 0.190 & 0.122 & 0.052 & 0.826 \\
\hline Riga & 0.935 & 0.027 & 0.038 & 0.372 & 0.432 & 0.195 & 0.141 & 0.050 & 0.809 \\
\hline Married & 0.936 & 0.023 & 0.041 & 0.365 & 0.460 & 0.175 & 0.163 & 0.045 & 0.792 \\
\hline Densely pop. & 0.923 & 0.033 & 0.044 & 0.341 & 0.451 & 0.208 & 0.134 & 0.061 & 0.805 \\
\hline Intermed. pop. & 0.942 & 0.026 & 0.032 & 0.400 & 0.300 & 0.300 & 0.091 & 0.073 & 0.836 \\
\hline Thinly pop. & 0.926 & 0.029 & 0.045 & 0.352 & 0.444 & 0.205 & 0.125 & 0.032 & 0.843 \\
\hline
\end{tabular}

b) Crisis: $2008-2011$

\begin{tabular}{|l|c|c|c|c|c|c|c|c|c|}
\hline & EE & EU & EN & UE & UU & UN & NE & NU & NN \\
\hline All & 0.882 & 0.063 & 0.055 & 0.361 & 0.422 & 0.217 & 0.123 & 0.086 & 0.791 \\
\hline Tertiary & 0.937 & 0.031 & 0.032 & 0.444 & 0.346 & 0.211 & 0.290 & 0.130 & 0.580 \\
\hline Secondary & 0.878 & 0.067 & 0.055 & 0.380 & 0.424 & 0.196 & 0.155 & 0.114 & 0.731 \\
\hline Primary & 0.778 & 0.112 & 0.110 & 0.262 & 0.455 & 0.283 & 0.064 & 0.049 & 0.887 \\
\hline Male & 0.873 & 0.078 & 0.049 & 0.365 & 0.459 & 0.176 & 0.118 & 0.094 & 0.788 \\
\hline Female & 0.891 & 0.049 & 0.061 & 0.355 & 0.372 & 0.272 & 0.127 & 0.080 & 0.793 \\
\hline $16-24$ & 0.768 & 0.116 & 0.116 & 0.319 & 0.393 & 0.288 & 0.086 & 0.076 & 0.838 \\
\hline $25-54$ & 0.904 & 0.063 & 0.033 & 0.388 & 0.449 & 0.163 & 0.233 & 0.154 & 0.613 \\
\hline $55-64$ & 0.839 & 0.043 & 0.119 & 0.283 & 0.330 & 0.388 & 0.078 & 0.036 & 0.886 \\
\hline Latvian & 0.892 & 0.055 & 0.052 & 0.389 & 0.391 & 0.220 & 0.127 & 0.080 & 0.793 \\
\hline Non-Latvian & 0.863 & 0.077 & 0.060 & 0.325 & 0.462 & 0.213 & 0.116 & 0.098 & 0.786 \\
\hline Riga & 0.888 & 0.059 & 0.053 & 0.378 & 0.414 & 0.208 & 0.122 & 0.091 & 0.786 \\
\hline Married & 0.900 & 0.052 & 0.049 & 0.392 & 0.399 & 0.208 & 0.171 & 0.092 & 0.737 \\
\hline Densely pop. & 0.885 & 0.067 & 0.048 & 0.360 & 0.439 & 0.201 & 0.124 & 0.110 & 0.766 \\
\hline Intermed. pop. & 0.915 & 0.059 & 0.026 & 0.433 & 0.418 & 0.149 & 0.097 & 0.049 & 0.854 \\
\hline Thinly pop. & 0.880 & 0.061 & 0.059 & 0.359 & 0.413 & 0.228 & 0.123 & 0.078 & 0.798 \\
\hline
\end{tabular}


c. Recovery: 2012-2016

1

\begin{tabular}{|l|l|l|l|l|l|l|l|l|c|}
\hline & EE & EU & EN & UE & UU & UN & NE & NU & NN \\
\hline all & 0.915 & 0.045 & 0.041 & 0.363 & 0.433 & 0.205 & 0.130 & 0.106 & 0.764 \\
\hline Tertiary & 0.961 & 0.017 & 0.021 & 0.451 & 0.326 & 0.222 & 0.274 & 0.121 & 0.605 \\
\hline Secondary & 0.919 & 0.039 & 0.042 & 0.350 & 0.390 & 0.260 & 0.152 & 0.098 & 0.750 \\
\hline Primary & 0.850 & 0.076 & 0.074 & 0.276 & 0.443 & 0.280 & 0.063 & 0.049 & 0.888 \\
\hline Male & 0.927 & 0.041 & 0.032 & 0.359 & 0.416 & 0.225 & 0.133 & 0.087 & 0.780 \\
\hline Female & 0.927 & 0.031 & 0.043 & 0.333 & 0.364 & 0.303 & 0.132 & 0.080 & 0.788 \\
\hline $16-24$ & 0.820 & 0.064 & 0.116 & 0.355 & 0.333 & 0.312 & 0.115 & 0.067 & 0.818 \\
\hline 25-54 & 0.940 & 0.036 & 0.024 & 0.371 & 0.422 & 0.206 & 0.222 & 0.149 & 0.629 \\
\hline 55-64 & 0.907 & 0.027 & 0.066 & 0.261 & 0.333 & 0.406 & 0.074 & 0.044 & 0.882 \\
\hline Latvian & 0.931 & 0.032 & 0.037 & 0.384 & 0.361 & 0.255 & 0.144 & 0.079 & 0.778 \\
\hline Non-Latvian & 0.916 & 0.044 & 0.040 & 0.297 & 0.438 & 0.265 & 0.109 & 0.092 & 0.800 \\
\hline Riga & 0.936 & 0.028 & 0.036 & 0.425 & 0.314 & 0.261 & 0.144 & 0.078 & 0.778 \\
\hline Married & 0.936 & 0.030 & 0.034 & 0.367 & 0.367 & 0.266 & 0.152 & 0.083 & 0.765 \\
\hline Densely pop. & 0.930 & 0.041 & 0.029 & 0.350 & 0.412 & 0.238 & 0.125 & 0.093 & 0.782 \\
\hline Intermed. pop. & 0.932 & 0.031 & 0.037 & 0.367 & 0.371 & 0.261 & 0.135 & 0.078 & 0.787 \\
\hline Thinly pop. & 0.922 & 0.035 & 0.043 & 0.336 & 0.394 & 0.269 & 0.134 & 0.081 & 0.784 \\
\hline
\end{tabular}

Source: Latvian Labour Force Survey, years 2002 - 2016. The transition from 2006 to 2007 is missing due to different coding of households. 


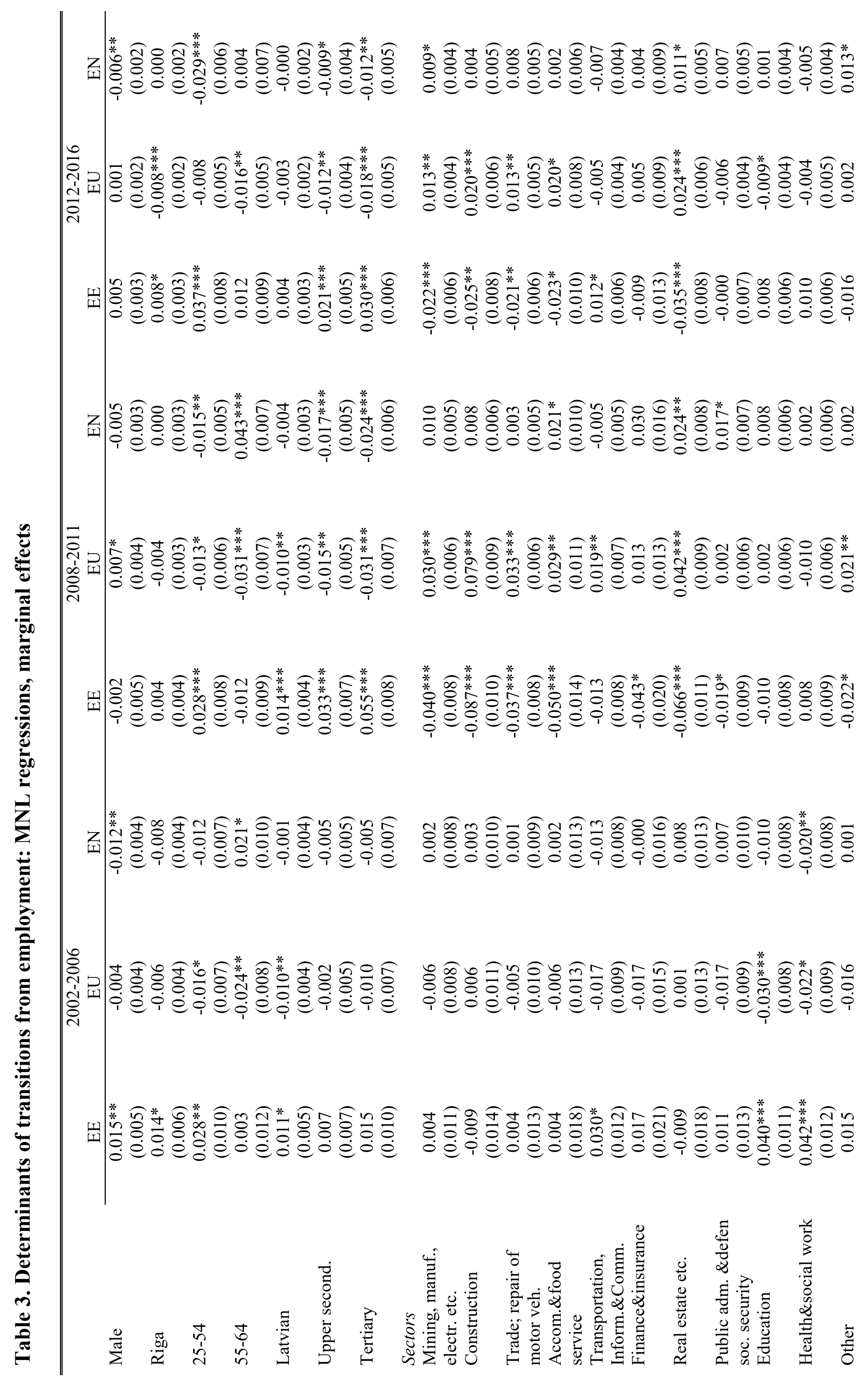




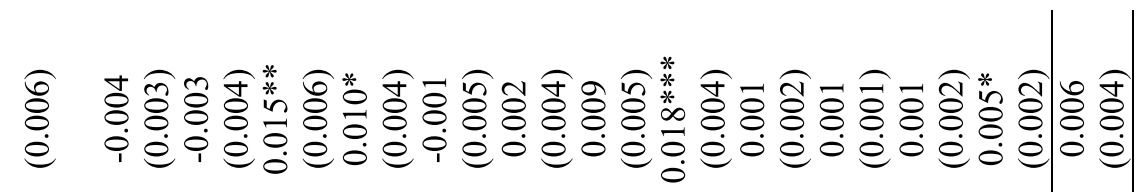

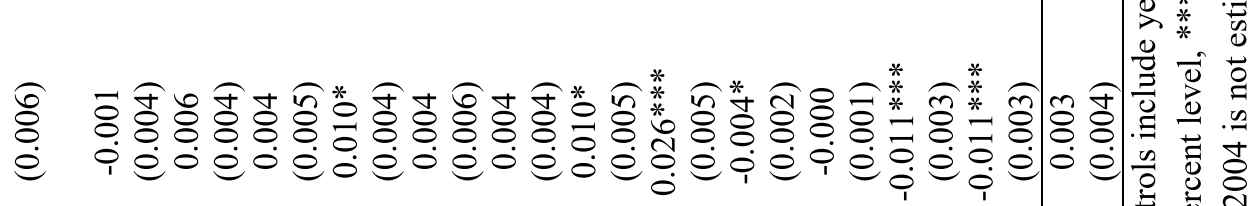

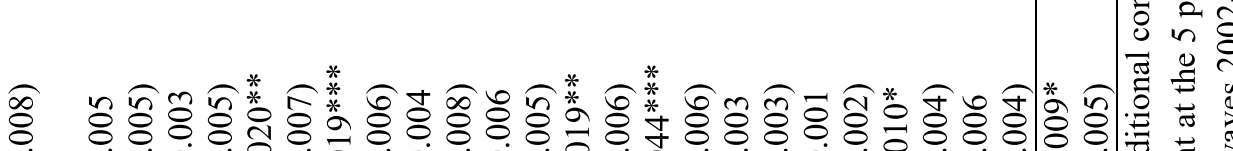

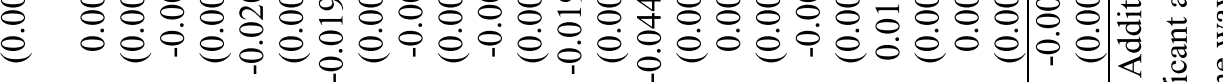

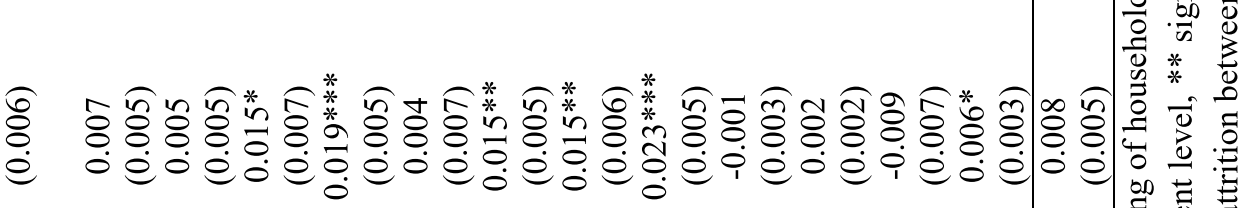

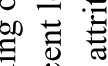

○ \&

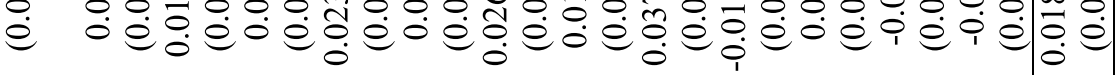
黄

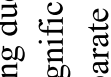

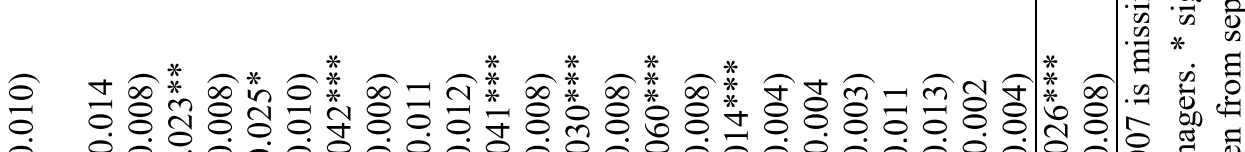

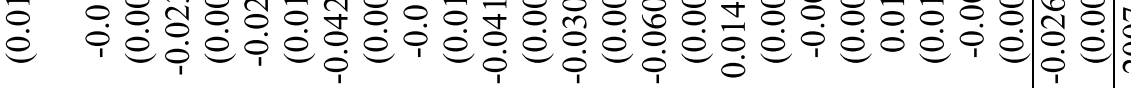

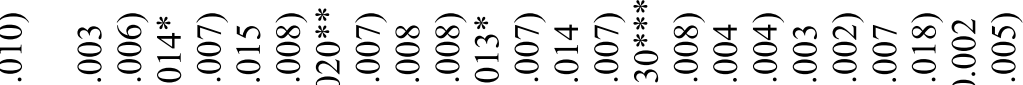

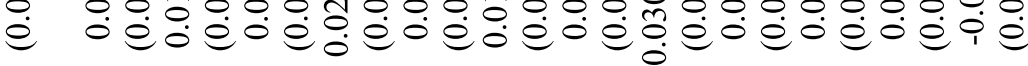

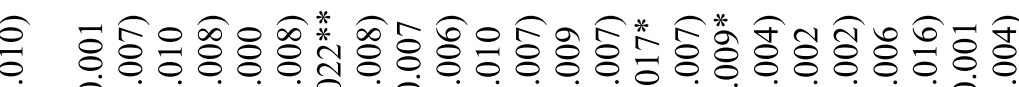

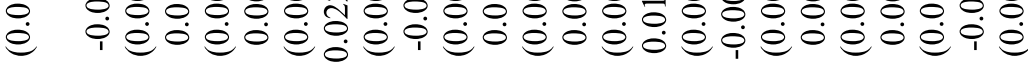

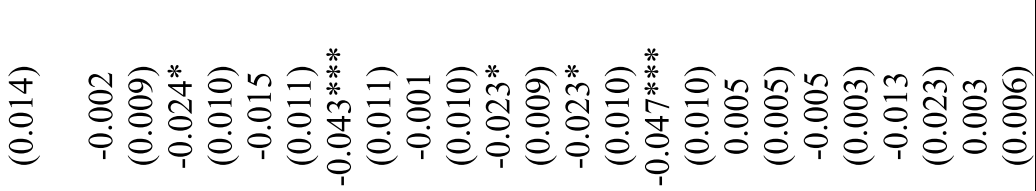

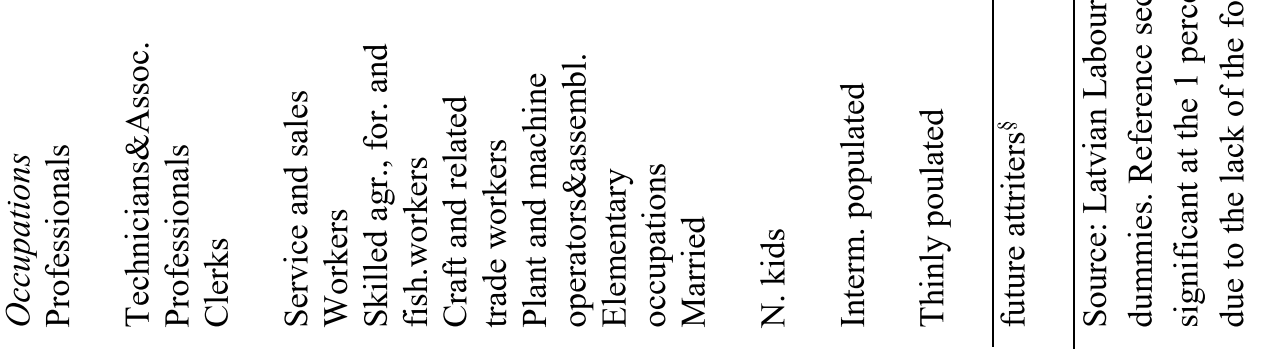




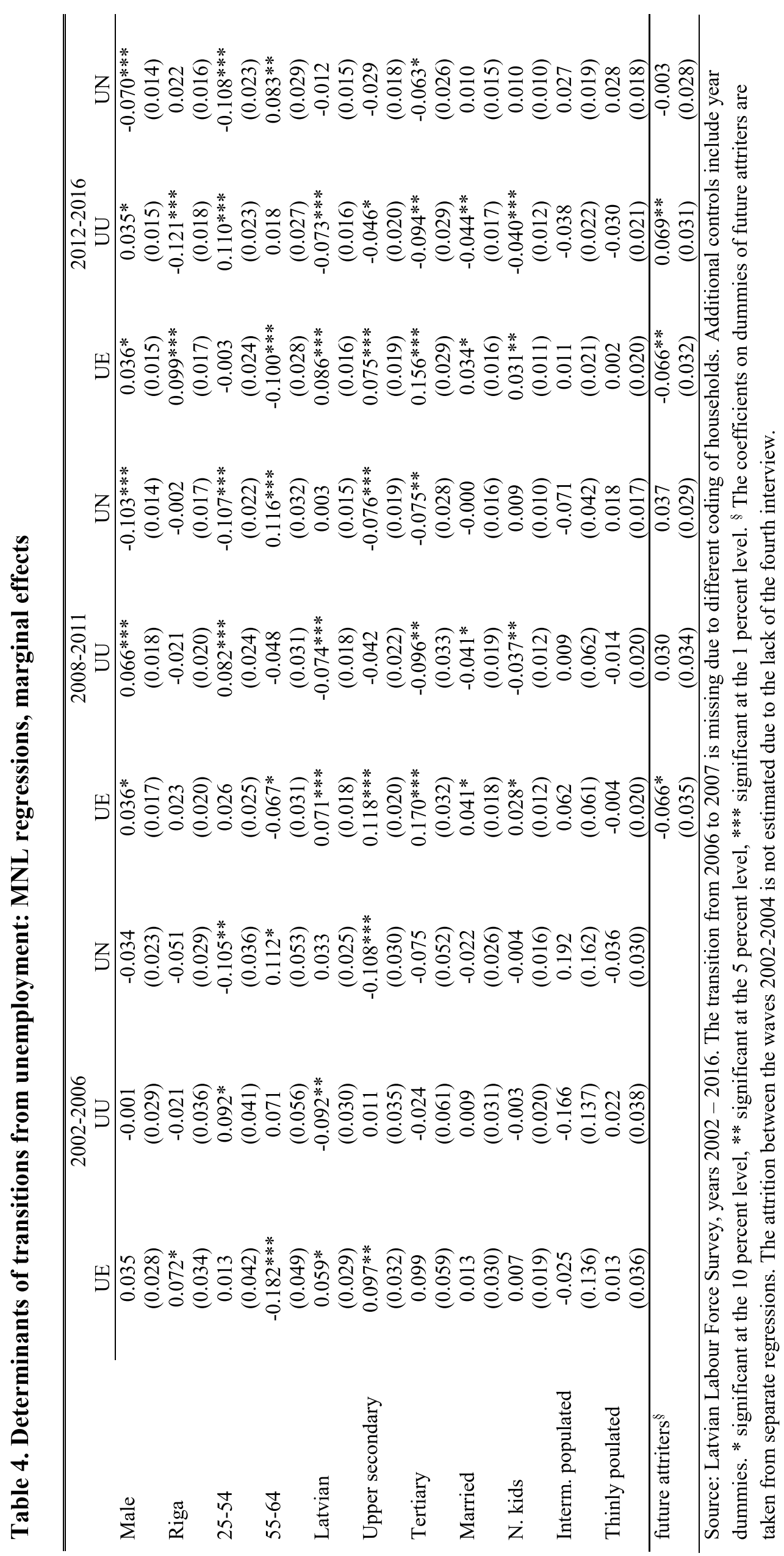




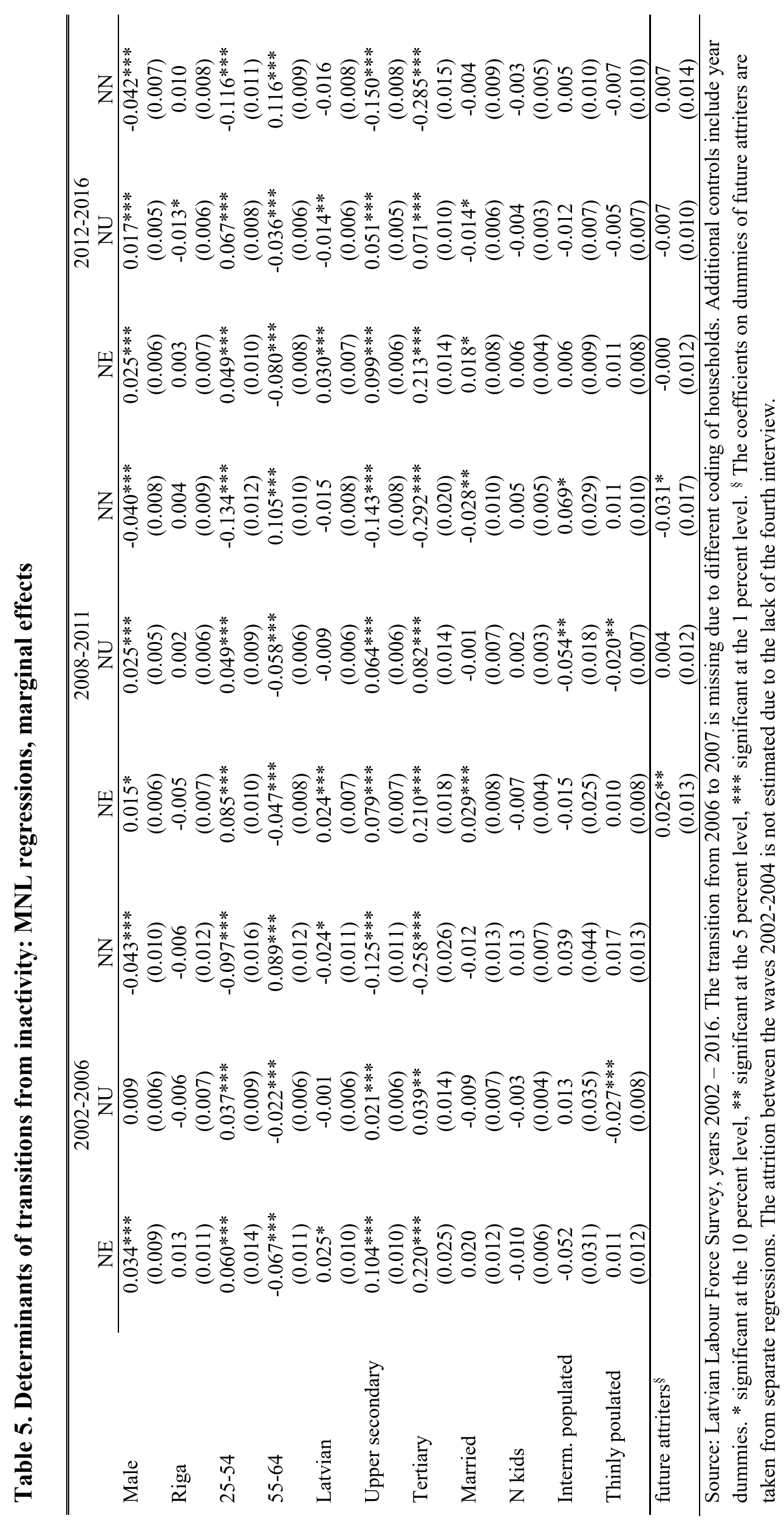




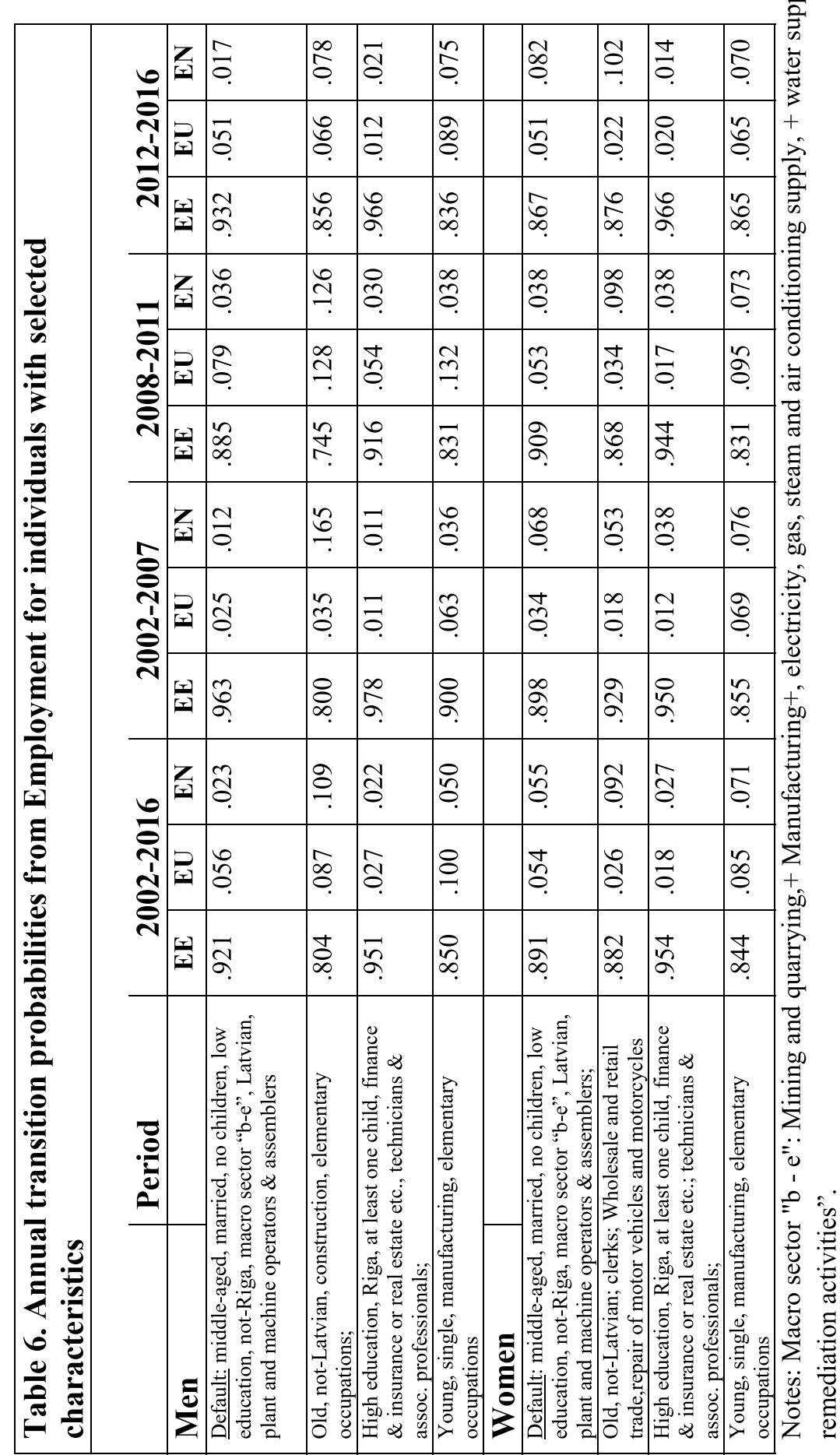




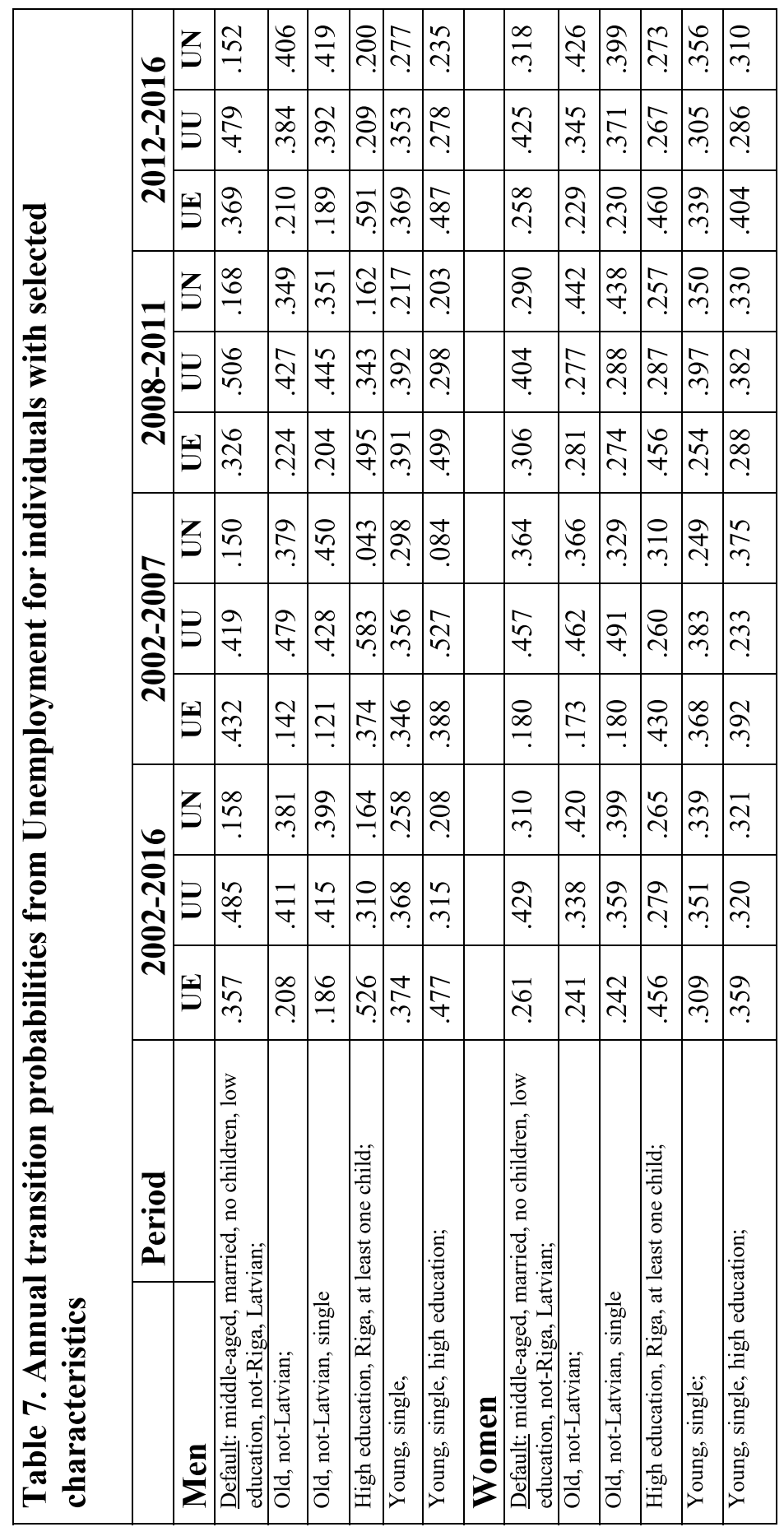




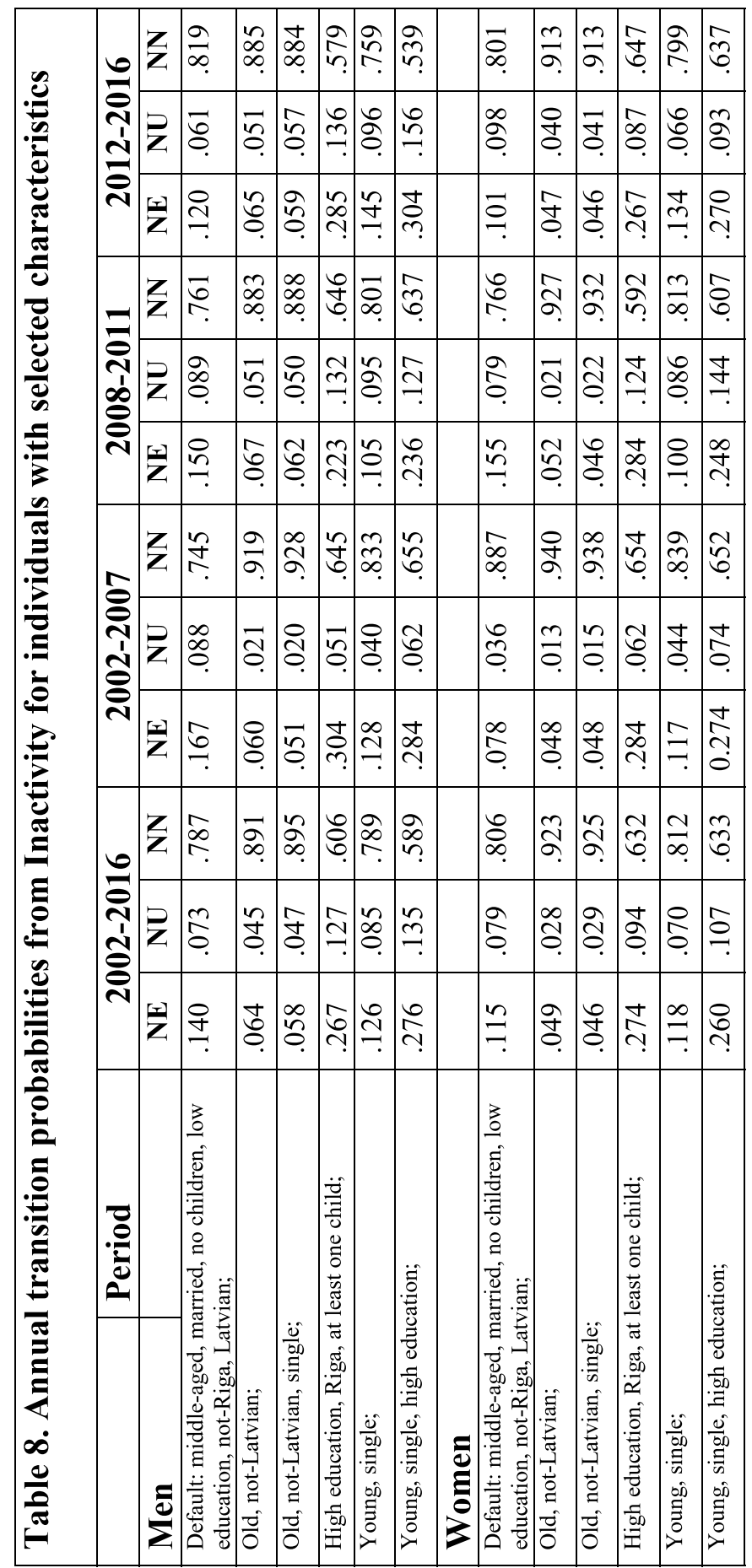


Table 9. Log real wage regressions with annual job-to-job movements

\begin{tabular}{|c|c|c|c|c|}
\hline & $\begin{array}{c}\text { OLS } \\
\text { (1) }\end{array}$ & $\begin{array}{l}\text { OLS } \\
\text { (2) }\end{array}$ & $\begin{array}{l}\text { OLS } \\
\text { (3) }\end{array}$ & $\begin{array}{l}\text { FE } \\
\text { (4) }\end{array}$ \\
\hline \multirow[t]{2}{*}{ Age } & $0.026 * * *$ & $0.021 * * *$ & $0.021 * * *$ & $0.140 * * *$ \\
\hline & $(0.002)$ & $(0.002)$ & $(0.002)$ & $(0.011)$ \\
\hline \multirow[t]{2}{*}{ Age sq } & $-0.000 * * *$ & $-0.000 * * *$ & $-0.000 * * *$ & $-0.001 * * *$ \\
\hline & $(0.000)$ & $(0.000)$ & $(0.000)$ & $(0.000)$ \\
\hline \multirow[t]{2}{*}{ Male } & $0.253 * * *$ & $0.320 * * *$ & $0.322 * * *$ & 0.000 \\
\hline & $(0.007)$ & $(0.007)$ & $(0.007)$ & (.) \\
\hline \multirow[t]{2}{*}{ Sec. edu. } & $0.244 * * *$ & $0.133 * * *$ & $0.131 * * *$ & 0.012 \\
\hline & $(0.012)$ & $(0.013)$ & $(0.013)$ & $(0.020)$ \\
\hline \multirow[t]{2}{*}{ Ter. Edu. } & $0.824 * * *$ & $0.437 * * *$ & $0.434 * * *$ & 0.023 \\
\hline & $(0.013)$ & $(0.015)$ & $(0.015)$ & $(0.022)$ \\
\hline \multirow[t]{2}{*}{2008} & $0.301 * * *$ & $0.307 * * *$ & $0.309 * * *$ & $0.206^{* * *}$ \\
\hline & $(0.020)$ & $(0.020)$ & $(0.020)$ & $(0.015)$ \\
\hline \multirow[t]{2}{*}{2009} & $0.435 * * *$ & $0.460 * * *$ & $0.457 * * *$ & $0.288 * * *$ \\
\hline & $(0.018)$ & $(0.019)$ & $(0.019)$ & $(0.014)$ \\
\hline \multirow[t]{2}{*}{2010} & $0.280 * * *$ & $0.308 * * *$ & $0.308 * * *$ & $0.062 * * *$ \\
\hline & $(0.018)$ & $(0.019)$ & $(0.019)$ & $(0.014)$ \\
\hline \multirow[t]{2}{*}{2011} & $0.226 * * *$ & $0.256^{* * *}$ & $0.255^{* * *}$ & $-0.033 *$ \\
\hline & $(0.018)$ & $(0.018)$ & $(0.018)$ & $(0.015)$ \\
\hline \multirow[t]{2}{*}{2012} & $0.300 * * *$ & $0.318 * * *$ & $0.315 * * *$ & $-0.034 *$ \\
\hline & $(0.020)$ & $(0.019)$ & $(0.019)$ & $(0.016)$ \\
\hline \multirow[t]{2}{*}{2013} & $0.352 * * *$ & $0.369 * * *$ & $0.364 * * *$ & $-0.034^{*}$ \\
\hline & $(0.019)$ & $(0.019)$ & $(0.018)$ & $(0.016)$ \\
\hline \multirow[t]{2}{*}{2014} & $0.840 * * *$ & $0.664 * * *$ & $0.659 * * *$ & -0.013 \\
\hline & $(0.021)$ & $(0.021)$ & $(0.021)$ & $(0.007)$ \\
\hline \multirow[t]{2}{*}{2015} & $0.925 * * *$ & $0.750 * * *$ & $0.746^{* * *}$ & \\
\hline & $(0.021)$ & $(0.021)$ & $(0.021)$ & \\
\hline \multirow[t]{2}{*}{ Oc. group2 } & & $-0.403 * * *$ & $-0.400 * * *$ & -0.023 \\
\hline & & $(0.009)$ & $(0.009)$ & $(0.021)$ \\
\hline \multirow[t]{2}{*}{ Oc. group3 } & & $-0.445 * * *$ & $-0.443 * * *$ & -0.010 \\
\hline & & $(0.011)$ & $(0.011)$ & $(0.035)$ \\
\hline \multirow[t]{2}{*}{ Oc. group4 } & & $-0.531 * * *$ & $-0.526 * * *$ & $-0.069^{*}$ \\
\hline & & $(0.010)$ & $(0.010)$ & $(0.029)$ \\
\hline \multirow[t]{2}{*}{ Job change } & & & $-0.133 * * *$ & -0.023 \\
\hline & & & $(0.013)$ & $(0.014)$ \\
\hline \multirow[t]{2}{*}{ Constant } & $4.980 * * *$ & $5.474 * * *$ & $5.506^{* * *}$ & $1.925 * * *$ \\
\hline & $(0.042)$ & $(0.044)$ & $(0.044)$ & $(0.269)$ \\
\hline R-squared & 0.179 & 0.255 & 0.258 & 0.089 \\
\hline Observations & 37001 & 33842 & 33842 & 33842 \\
\hline \multicolumn{5}{|c|}{$\begin{array}{l}\text { Source: EU SILC 2007-2015. Notes: Robust standard errors in parentheses. * significant at the } 10 \text { percent level, } \\
\text { significant at the } 5 \text { percent level, } * * * \text { significant at the } 1 \text { percent level. Sample includes individuals } 16-64 \text { years old not } \\
\text { in the armed forces. Job change equals } 1 \text { if a person changes job since last year. Oc_group1 (reference category) refers } \\
\text { to legislators, senior officials, managers, professionals and associated professionals; Oc_group2 refers to clerks, } \\
\text { service workers, shop and sales workers; Oc_group } 3 \text { refers to skilled agricultural and fishery workers, craft and related } \\
\text { trades workers; Oc group4 refers to plant and machine operators and assemblers, elementary occupations. }\end{array}$} \\
\hline
\end{tabular}




\section{Table 10. Coefficients of interaction terms of job change and occupational mobility}

\begin{tabular}{lcc}
\hline \hline & $(1)$ & $(2)$ \\
Job change & $-0.155^{* *}$ & -0.092 \\
& $(0.057)$ & $(0.056)$ \\
Job change, Upward mobility & $-0.229^{* * *}$ & -0.030 \\
& $(0.055)$ & $(0.054)$ \\
Job change, Downward mobility & $-0.249^{* * *}$ & $-0.326^{* * *}$ \\
& $(0.058)$ & $(0.057)$ \\
Occupations included & No & Yes \\
Constant & $5.129^{* * *}$ & $5.582^{* * *}$ \\
& $(0.073)$ & $(0.073)$ \\
R-squared & 0.175 & 0.262 \\
Observations & 31341 & 28703 \\
\hline Soure: & Do
\end{tabular}

Source: EU SILC 2007-2015. Notes: Coefficients from pooled OLS regressions are reported. Robust standard errors in parentheses. * significant at the 10 percent level, ${ }^{* *}$ significant at the 5 percent level, ${ }^{* * *}$ significant at the 1 percent level. Sample includes individuals 16-64 years old not in the armed forces. All regressions include the same variables as in Table 7. Dependent variable: $\log$ of real wages. 
Figure 1a. Labor market aggregates in Latvia: Employment and labor force participation

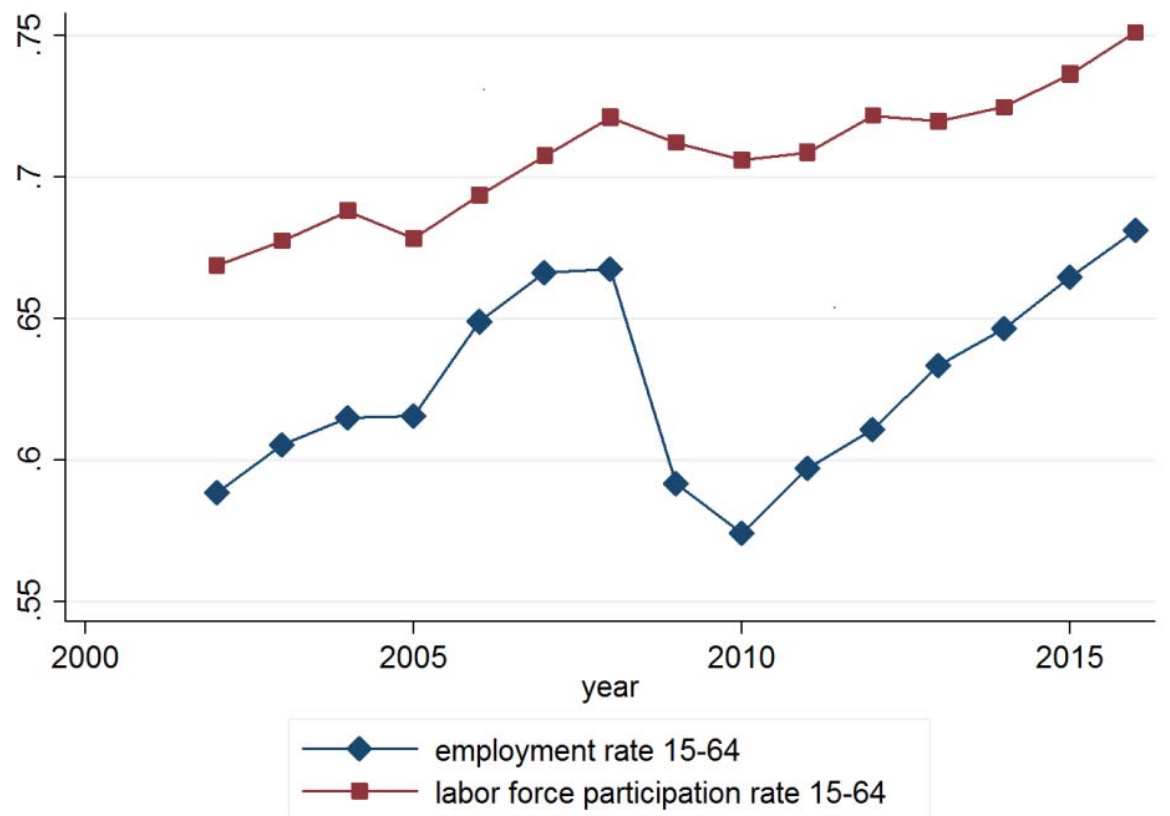

Figure 1b. Labor market aggregates in Latvia: unemployment and self-employment

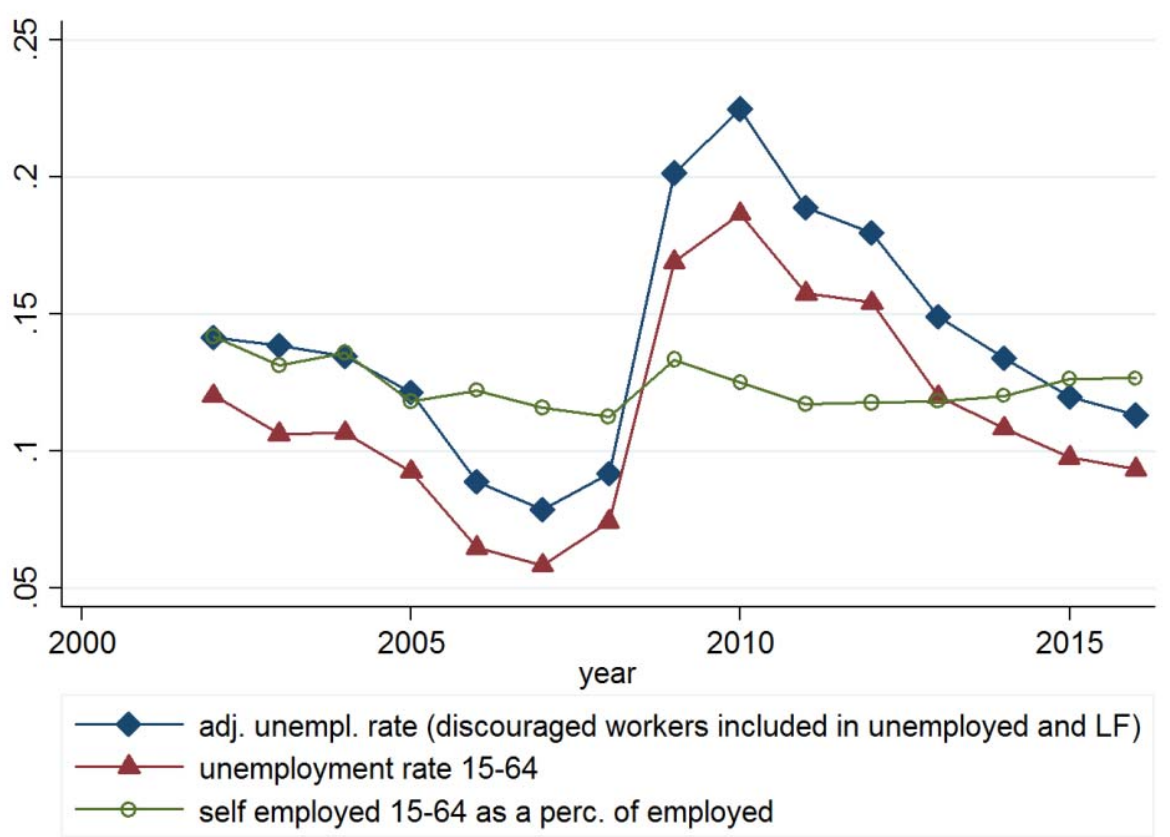

Source: Latvian LFS. 
Figure 2: Aggregates of underemployment

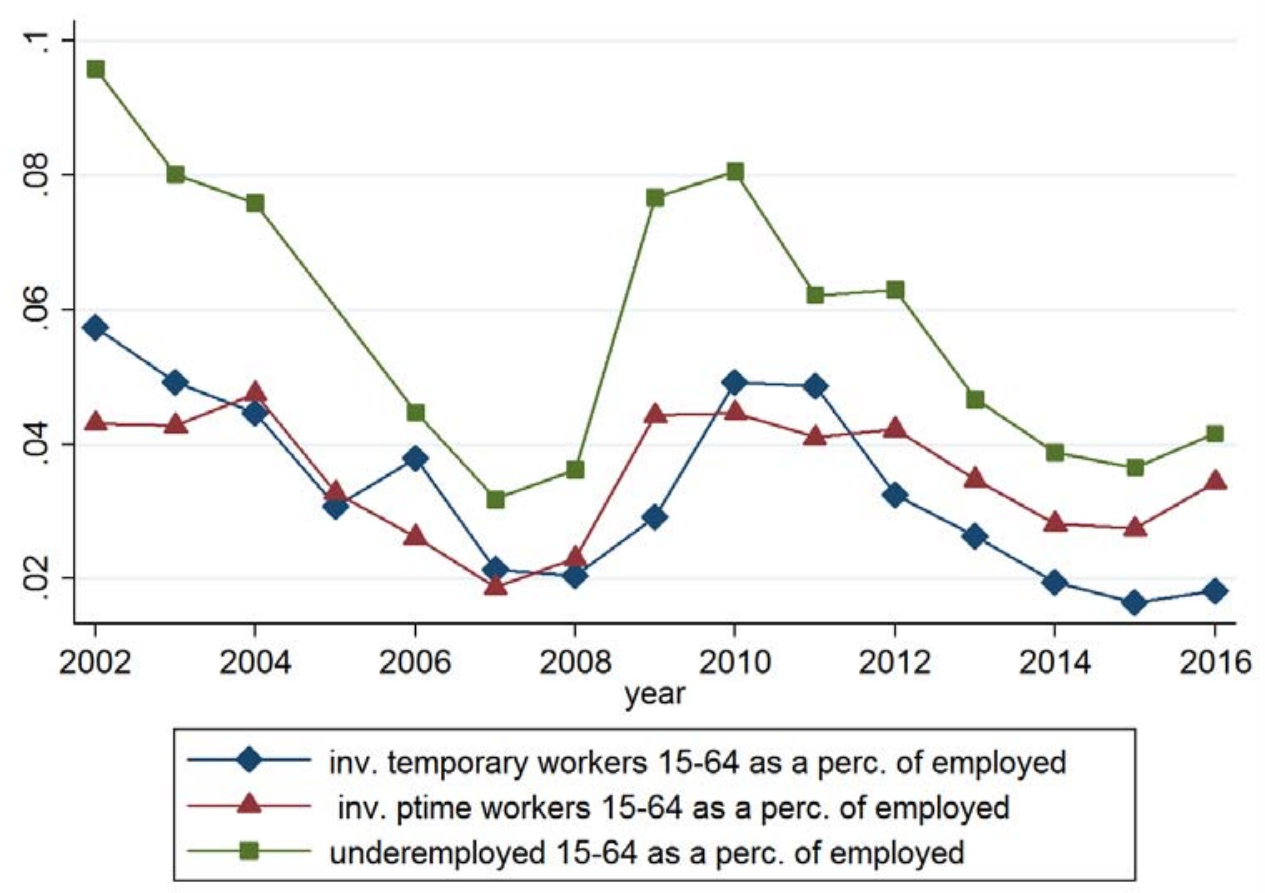

Source: Latvian LFS. 


\section{APPENDIX}

Table A1. Descriptive Statistics for the year 2007

\begin{tabular}{|c|c|c|}
\hline Variable & Mean & St. Dev. \\
\hline Male & 0.486 & $(0.500)$ \\
\hline Riga & 0.301 & $(0.459)$ \\
\hline Latvian & 0.651 & $(0.477)$ \\
\hline $16-24$ & 0.075 & $(0.263)$ \\
\hline $25-54$ & 0.747 & $(0.435)$ \\
\hline $55-64$ & 0.178 & $(0.383)$ \\
\hline Primary ed. & 0.118 & $(0.322)$ \\
\hline Upper Secondaryed. & 0.639 & $(0.480)$ \\
\hline Tertiary ed. & 0.244 & $(0.429)$ \\
\hline Married & 0.581 & $(0.494)$ \\
\hline Nr. Children & 0.359 & $(0.678)$ \\
\hline Agriculture, forestry and fishing & 0.099 & $(0.298)$ \\
\hline Mining and manuf. & 0.209 & $(0.407)$ \\
\hline Construction & 0.108 & $(0.310)$ \\
\hline Trade & 0.145 & $(0.352)$ \\
\hline Accom.\&food service & 0.025 & $(0.156)$ \\
\hline Transportation & 0.084 & $(0.277)$ \\
\hline Finance\&insurance & 0.013 & $(0.113)$ \\
\hline Real estate & 0.047 & $(0.212)$ \\
\hline Public adm.\&defence & 0.065 & $(0.247)$ \\
\hline Education & 0.093 & $(0.290)$ \\
\hline Health\&social work & 0.060 & $(0.236)$ \\
\hline Arts\&otherservices & 0.054 & $(0.226)$ \\
\hline Legislators, officials and managers & 0.093 & $(0.290)$ \\
\hline Professionals & 0.131 & $(0.337)$ \\
\hline Technicians & 0.151 & $(0.358)$ \\
\hline Clerks & 0.045 & $(0.206)$ \\
\hline Service workers & 0.117 & $(0.322)$ \\
\hline Skilled agr.fish.workers & 0.047 & $(0.210)$ \\
\hline Craft workers & 0.153 & $(0.360)$ \\
\hline Operators\&assemblers & 0.118 & $(0.322)$ \\
\hline Elem. Occupations & 0.147 & $(0.354)$ \\
\hline Urban & 0.316 & $(0.465)$ \\
\hline Suburban & 0.019 & $(0.135)$ \\
\hline Rural & 0.665 & $(0.472)$ \\
\hline
\end{tabular}

Source: Latvian LFS. Notes: All time variant characteristics refer to 2007 and are as in the MNL regressions on transitions from 2007 to 2008 . 
Table A2. Transition probability matrices for the boom and crisis years

a. Boom preceding crisis 2007 to 2008

\begin{tabular}{|l|c|c|c|c|c|c|c|c|c|}
\hline & EE & EU & EN & UE & UU & UN & NE & NU & NN \\
\hline All & 0.948 & 0.030 & 0.022 & 0.531 & 0.217 & 0.253 & 0.165 & 0.050 & 0.784 \\
\hline Tertiary & 0.975 & 0.016 & 0.010 & 0.646 & 0.146 & 0.208 & 0.429 & 0.086 & 0.486 \\
\hline Secondary & 0.944 & 0.031 & 0.024 & 0.610 & 0.174 & 0.216 & 0.210 & 0.070 & 0.720 \\
\hline Primary & 0.912 & 0.055 & 0.032 & 0.303 & 0.343 & 0.354 & 0.090 & 0.027 & 0.883 \\
\hline Male & 0.949 & 0.035 & 0.016 & 0.542 & 0.281 & 0.177 & 0.156 & 0.055 & 0.789 \\
\hline Female & 0.948 & 0.026 & 0.027 & 0.518 & 0.143 & 0.339 & 0.172 & 0.047 & 0.781 \\
\hline $16-24$ & 0.876 & 0.073 & 0.051 & 0.522 & 0.145 & 0.333 & 0.118 & 0.040 & 0.842 \\
\hline 25-54 & 0.957 & 0.029 & 0.015 & 0.561 & 0.234 & 0.205 & 0.301 & 0.094 & 0.606 \\
\hline 55-64 & 0.941 & 0.019 & 0.040 & 0.383 & 0.234 & 0.383 & 0.108 & 0.023 & 0.869 \\
\hline Latvian & 0.955 & 0.024 & 0.021 & 0.515 & 0.223 & 0.262 & 0.159 & 0.047 & 0.794 \\
\hline Non- & 0.936 & 0.042 & 0.023 & 0.552 & 0.208 & 0.240 & 0.177 & 0.057 & 0.766 \\
Latvian & & & & & & & & & \\
\hline Riga & 0.954 & 0.027 & 0.019 & 0.637 & 0.121 & 0.242 & 0.185 & 0.054 & 0.761 \\
\hline
\end{tabular}

\section{b. Crisis year2008 to 2009}

\begin{tabular}{|l|c|c|c|c|c|c|c|c|c|}
\hline & EE & EU & EN & UE & UU & UN & NE & NU & NN \\
\hline All & 0.874 & 0.083 & 0.043 & 0.284 & 0.476 & 0.239 & 0.112 & 0.086 & 0.802 \\
\hline Tertiary & 0.932 & 0.037 & 0.032 & 0.365 & 0.385 & 0.250 & 0.235 & 0.101 & 0.665 \\
\hline Secondary & 0.867 & 0.092 & 0.041 & 0.321 & 0.483 & 0.196 & 0.159 & 0.117 & 0.724 \\
\hline Primary & 0.788 & 0.134 & 0.077 & 0.191 & 0.494 & 0.315 & 0.055 & 0.057 & 0.888 \\
\hline Male & 0.847 & 0.108 & 0.045 & 0.277 & 0.512 & 0.211 & 0.096 & 0.089 & 0.815 \\
\hline Female & 0.899 & 0.060 & 0.041 & 0.294 & 0.430 & 0.276 & 0.123 & 0.083 & 0.793 \\
\hline $16-24$ & 0.807 & 0.152 & 0.041 & 0.218 & 0.495 & 0.287 & 0.079 & 0.068 & 0.853 \\
\hline 25-54 & 0.889 & 0.086 & 0.026 & 0.322 & 0.481 & 0.198 & 0.203 & 0.162 & 0.634 \\
\hline 55-64 & 0.841 & 0.050 & 0.109 & 0.200 & 0.429 & 0.371 & 0.078 & 0.038 & 0.884 \\
\hline Latvian & 0.886 & 0.075 & 0.039 & 0.305 & 0.453 & 0.242 & 0.117 & 0.077 & 0.806 \\
\hline $\begin{array}{l}\text { Non- } \\
\text { Latvian }\end{array}$ & 0.851 & 0.098 & 0.050 & 0.258 & 0.507 & 0.236 & 0.102 & 0.103 & 0.795 \\
\hline Riga & 0.874 & 0.080 & 0.046 & 0.272 & 0.442 & 0.286 & 0.106 & 0.082 & 0.812 \\
\hline
\end{tabular}

c. 2009 to 2010

\begin{tabular}{|l|c|c|c|c|c|c|c|c|c|}
\hline & EE & EU & EN & UE & UU & UN & NE & NU & NN \\
\hline All & 0.892 & 0.063 & 0.045 & 0.329 & 0.460 & 0.211 & 0.117 & 0.110 & 0.773 \\
\hline Tertiary & 0.930 & 0.036 & 0.034 & 0.409 & 0.409 & 0.181 & 0.317 & 0.144 & 0.540 \\
\hline Secondary & 0.889 & 0.069 & 0.042 & 0.342 & 0.465 & 0.194 & 0.136 & 0.146 & 0.718 \\
\hline Primary & 0.802 & 0.101 & 0.097 & 0.246 & 0.472 & 0.282 & 0.060 & 0.061 & 0.879 \\
\hline Male & 0.883 & 0.079 & 0.038 & 0.331 & 0.490 & 0.178 & 0.120 & 0.124 & 0.757 \\
\hline Female & 0.901 & 0.050 & 0.050 & 0.324 & 0.413 & 0.263 & 0.114 & 0.099 & 0.787 \\
\hline $16-24$ & 0.852 & 0.103 & 0.044 & 0.274 & 0.447 & 0.279 & 0.086 & 0.105 & 0.809 \\
\hline 25-54 & 0.909 & 0.063 & 0.028 & 0.354 & 0.486 & 0.160 & 0.200 & 0.189 & 0.611 \\
\hline 55-64 & 0.837 & 0.050 & 0.113 & 0.276 & 0.346 & 0.378 & 0.080 & 0.037 & 0.884 \\
\hline Latvian & 0.901 & 0.058 & 0.041 & 0.362 & 0.423 & 0.215 & 0.128 & 0.107 & 0.765 \\
\hline $\begin{array}{l}\text { Non- } \\
\text { Latvian }\end{array}$ & 0.877 & 0.072 & 0.051 & 0.285 & 0.509 & 0.206 & 0.096 & 0.116 & 0.788 \\
\hline Riga & 0.891 & 0.065 & 0.043 & 0.346 & 0.471 & 0.183 & 0.103 & 0.127 & 0.770 \\
\hline
\end{tabular}

